\title{
MITOCHONDRIA TARGETING TO OPPOSE THE PROGRESSION OF NONALCOHOLIC FATTY LIVER DISEASE
}

Ignazio Grattagliano ${ }^{a, b}$, Liliana P. Montezinhoc, d, Paulo J. Oliveirac ${ }^{c}$, Gema Frühbeck ${ }^{\mathrm{e}, \mathrm{fg}, \mathrm{h}}$, Javier Gómez-Ambrosi e,f,g, Fabrizio Montecuccoi,j,k, Federico Carbone', Mariusz R. Wieckowski', David Q.-H. Wang ${ }^{\mathrm{m}}$, Piero Portincasa ${ }^{\mathrm{a},{ }^{*}}$

aClinica Medica "A. Murri”, Department of Biomedical Sciences and Human Oncology, University of Bari Medical School, Bari, Italy

bItalian College of General Practitioners and Primary Care, Bari, Italy ${ }^{c} \mathrm{CNC}$ - Center for Neuroscience and Cell Biology, University of Coimbra, UC-Biotech Building, Biocant Park - Cantanhede, Portugal

${ }^{d}$ Center for Investigation Vasco da Gama (CIVG), Department of Veterinary Medicine, Escola Universitária Vasco da Gama, Coimbra, Portugal;

eMetabolic Research Laboratory, Clínica Universidad de Navarra, Pamplona, Spain;

fCIBER Fisiopatología de la Obesidad y Nutrición (CIBEROBN), Instituto de Salud Carlos III, Pamplona, Spain;

gObesity and Adipobiology Group, Instituto de Investigación Sanitaria de Navarra (IdiSNA), Pamplona, Spain;

hDepartment of Endocrinology \& Nutrition, Clínica Universidad de Navarra, Pamplona, Spain; 'First Clinic of Internal Medicine, Department of Internal Medicine, University of Genoa, 6 viale Benedetto XV, 16132 Genoa, Italy

'Ospedale Policlinico San Martino, 10 Largo Benzi, 16132 Genoa, Italy.

${ }^{k}$ Centre of Excellence for Biomedical Research (CEBR), University of Genoa, 9 Viale Benedetto XV, 16132 Genoa, Italy.

'Nencki Institute of Experimental Biology, PAS, Warsaw, Poland.

mDepartment of Medicine, Division of Gastroenterology and Liver Diseases, Marion Bessin Liver Research Center, Albert Einstein College of Medicine, Bronx, NY 10461, USA 


\section{*Address correspondence to:}

Piero Portincasa, M.D., Ph.D.,

Professor of Internal Medicine

University of Bari Medical School

Clinica Medica "A. Murri"

Department of Biosciences and Human Oncology (DIMO)

Policlinico Hospital, 70124 Bari, Italy

Phone: +39-080-5478227; Fax: +39-080-5478232;

Email address: piero.portincasa@uniba.it

Key words: fatty liver; mitochondria; nitrosative stress; nonalcoholic fatty liver disease; oxidative stress;

Abbreviations: ANG, angiotensin; ATP, adenosine triphosphate; BCAA, branched-chain amino acids; DAG, diacylglycerol; ER, endoplasmic reticulum; Fe/S, iron-sulfur; FFA, free fatty acid; GPD2, glycerol phosphatase dehydrogenase-2; GFP, green-fluorescence protein; GSH, glutathione; HCC, hepatocellular carcinoma; iNOs, inducible nitric oxide synthase; $\mathrm{KGDH}, \alpha-$ ketoglutarate dehydrogenase; LCFA, long chain fatty acids; MAM, mitochondria-associated membranes; MPC, mitochondrial pyruvate carrier; mtDNA, mitochondrial DNA; MPTP, mitochondrial permeability transition pore; NAFL, nonalcoholic fatty liver; NAFLD, nonalcoholic fatty liver disease; NASH, nonalcoholic steatohepatitis; NO, nitric oxide; NOX4, NADPH oxidase-4; PDH, pyruvate dehydrogenase; PSSG, protein mixed disulphides; PSH, protein sulfhydryl; ROS, reactive oxygen species; SAME, S-adenosyl-L-methionine; SOD, superoxide dismutase; TCA, tricarboxylic acids; TFAM, transcription factor A, TG, triglycerides; TNF- $\alpha$, tumor necrosis factor-alpha. 


\section{Acknowledgements}

M.R.W., P.J.O., and P.P., gratefully acknowledge the financial support for this research from the FOIE GRAS and mtFOIE GRAS projects. These projects received funding from the European Union's Horizon 2020 Research and Innovation programme under the Marie Skłodowska-Curie Grant Agreement No. 722619 (FOIE GRAS) and Grant Agreement No. 734719 (mtFOIE GRAS).

\section{Notes}

Compliance with ethical standards

\section{Conflicts of interest}

The Authors declare that they have no conflicts of interest.

\section{Statement of human and animal rights}

Not applicable.

\section{Informed consent}

Not applicable. 


\section{WHAT IS ALREADY KNOWN ABOUT THIS SUBJECT}

- Nonalcoholic fatty liver disease (NAFLD) is the most frequent chronic liver disease in developed countries and puts the populations at risk of evolution towards liver fibrosis, cirrhosis and hepatocellular carcinoma

- Mitochondrial dysfunction is involved in the onset of nonalcoholic fatty liver disease (NAFLD) and contributes to the progression from NAFLD to nonalcoholic steatohepatitis (NASH)

- Mitochondria could be a target to improve liver function in NAFLD

\section{WHAT THIS STUDY ADDS}

- A description of complex mechanisms involved in mitochondrial dysfunction in NAFLD and steatohepatitis

- Identification of potential therapeutic interventions, either in use or experimental, able to improve mitochondrial function in NAFLD 


\section{ABSTRACT}

Nonalcoholic fatty liver disease (NAFLD) is a condition characterized by the excessive accumulation of triglycerides in hepatocytes. NAFLD is the most frequent chronic liver disease in developed countries, and is often associated with metabolic disorders such as obesity and type 2 diabetes. NAFLD definition encompasses a spectrum of chronic liver abnormalities, ranging from simple steatosis (NAFL), to steatohepatitis (NASH), significant liver fibrosis, cirrhosis, and hepatocellular carcinoma. NAFLD, therefore, represents a global public health issue. Mitochondrial dysfunction occurs in NAFLD, and contributes to the progression to the necro-inflammatory and fibrotic form (NASH). Disrupted mitochondrial function is associated with a decrease in the energy levels and impaired redox balance, and negatively affects cell survival by altering overall metabolism and subcellular trafficking. Such events reduce the tolerance of hepatocytes towards damaging hits, and favour the injurious effects of extracellular factors. Here, we discuss the role of mitochondria in NAFLD and focus on potential therapeutic approaches aimed at preserving mitochondrial function. 


\section{INTRODUCTION}

Nonalcoholic fatty liver disease (NAFLD) includes a spectrum of disorders ranging from the simple liver steatosis to nonalcoholic steatohepatitis (NASH) with increasing inflammation and fibrosis (Figure 1), to cirrhosis and its complications, including the potential evolution to the hepatocellular carcinoma. NAFLD develops in the absence of other known causes of secondary accumulation of fat (i.e. relevant alcohol consumption, viruses). The prevalence of NAFLD is growing alarmingly worldwide with a clear association with metabolic diseases such as obesity, insulin resistance, type 2 diabetes, and dyslipidemia [1, 2]. The existence of a bidirectional relationship between NAFLD and various components of the metabolic syndrome points to a strong association between NAFLD and cardiovascular disease (CVD) morbidity and mortality. In fact, NAFLD may strongly contribute to the development of hypertension, diabetes and cardiovascular disease [3].

The processes leading to NAFLD are multifactorial. Overnutrition and fat accumulation in hepatocytes in the presence of insulin resistance in genetically predisposed individuals are major factors leading to the onset and progression to NASH. Among the genetic factors, polymorphisms in genes like PNPLA3 (which encodes patatin-like phospholipase domaincontaining protein 3) and TM6SF2 (which encodes transmembrane 6 superfamily member 2) could govern the severity of steatosis/steatohepatitis [4, $\underline{5}$ ] even in lean subjects [6]. Hepatocytes are cells intensively specialized in a variety of metabolic and detoxification processes. Therefore, mitochondria in hepatocytes are not only particularly prone to the effects of altered substrate influx but also trigger signalling pathways which may lead to cell injury (e.g. cytochrome c release) or cell protection (e.g. increased ATP generation). Mitochondrial dysfunction has an inevitably negative impact on energy generation as well as on the maintenance of ionic and redox gradients, thus being determinant for the progression of NAFLD toward NASH $[\underline{7}, \underline{8}]$. Furthermore, morphological alterations in mitochondria (crystalline inclusions, disruption of cristae) are associated with their functional impairment $[\underline{9}$, 
10]. This review discusses the critical role of mitochondria in the development and progression of NAFLD and points out to potential therapeutic interventions.

\section{MECHANISMS OF HEPATOCYTE TOXIC FAT ACCUMULATION IN NAFLD}

The mitochondrial damage that occurs in NAFLD is the consequence of a complex and multifactorial cascade of events involving long-chain fatty acids (LCFA) and triglycerides (TGs). The steps modulate the onset, and progression of liver steatosis. TGs form by the combination of one molecule of glycerol connected to three molecules of LCFA. LCFA are essential components of diets and are involved in a number of vital processes including energy production, energy storage, synthesis of plasma membrane, and anchorage of proteins. Hormone-like properties of LCFA include nuclear receptor-mediated (HNF4, PPAR) gene expression, activation of the G-protein-coupled receptor (GPCR) GPR40 and insulin release by $\beta$-cells. In addition, LCFA activate the innate immune response by modulating cellular tolllike receptor (TLR) signalling, and suppress food intake by acting in a subpopulation of hypothalamic neurons (with inhibition of the release of neuropeptide $Y$ (NPY) and Agoutirelated protein $(\mathrm{AgRP}))$.

$\underline{\text { TGs are physiologically stored within the adipocytes in the postprandial period and released }}$ intermittently during lipolysis, when needed. Small lipid droplets are found normally in hepatocytes [11, 12] and cardiomyocytes [13] but with the ongoing expansion of visceral adiposity, insulin resistance, de-repression of adipocyte lipases, and lipolysis ("obesogenic scenario"), a massive release of LCFA occurs into the splanchnic circulation towards the liver, striated muscle, cardiomyocytes, and pancreas. In these tissues, both the excess of LCFA and TG contribute to lipotoxicity, leading to clinical consequences such as NAFLD, and obesity cardiomyopathy $[14,15]$ (Figure 2). Mathematical algorithms model LCFA uptake according to protein-mediated transport of LCFA anions (saturable transport $\approx 95 \%$ ) and passive transmembrane diffusion of protonated LCFA (unsaturable transport) $[16,17]$. In the obesogenic scenario, the uptake of LCFA is upregulated in the liver [12], cardiomyocytes [18], 
and adipose tissues [19]. Uptake of LCFA is up-regulated before weight gain [20], while it is down-regulated after weight loss [21]. In addition, Vmax of LCFA intake progressively increases from non-obese to obese to super-obese patients [17] in both omental $[17,22]$ and subcutaneous [19] fat. We could speculate that events governing LCFA intake, work simultaneously at different tissue levels.

As depicted in Figure $\mathbf{3 A}$, increased visceral adiposity is associated with local and inflammatory changes due to macrophagic-mediated inflammation, upregulated adipocytokines and change in the of levels of adipocyte-derived hormones. In the liver, LCFA influx is regulated by protein transporters: fatty acid translocase (FAT) or class B scavenger receptor (CD36) [23], and fatty acid transporting polypeptide (FATP) family [24-28], as well as others [29, 30], including plasma membrane fatty acid binding protein (FABPpm) [31-34], caveolin-1 (CAV1) $[30,35]$. Dietary fat contributes to the hepatic uptake of LCFA and of triglycerides via low-density lipoprotein (LDL) receptor. Dietary and/or serum sugars enhances de novo lipogenesis [36] while insulin and glucose induce up-regulation of the carbohydrate$\underline{\text { responsive element-binding protein }(\mathrm{ChREBP}) \text { and sterol regulatory element-binding protein } 1}$ (SREBP1) which will further increase intrahepatic lipid supply by about $25 \%[37,38]$. Insulindependent pathways might involve endoplasmic reticulum stress to activate SREBP1 [39]. The intestinal microbiota can also contribute to NAFLD (i.e. dysbiosis [40], over-extraction of dietary nutrients [41], increased intestinal permeability [42], intestinal degradation of choline with negative effect on lipid homeostasis [36, 43-48], and bacteria and/or bacterial product translocation of endotoxins and endogenous ethanol via the portal circulation [49]). Fat accumulation is facilitated upon the ongoing decrease of very low-density lipoprotein (VLDL) assembly and secretion, decreased mobilization of triglycerides, diminished $\beta$-oxidation of LCFA, and decreased synthesis of ApoB100 [15]. Under such conditions, intrahepatic lipids are synthesized by expanded de novo lipogenesis plus dietary fat influx (40\%) and adipose 
tissue lipolysis (60\%) [50]. LCFA conversion to triglycerides might initially limit the ongoing damage leading to hepatic cytotoxicity and steatohepatitis.

Indeed, simple steatosis is an early and largely reversible form of NAFLD, while NASH represents the manifestation of hepatocyte injury/death and the resultant wound-healing process. The histologic picture resembles that of alcoholic hepatitis and evolution towards more severe forms of fibrosis, cryptogenic cirrhosis and hepatocellular carcinoma is possible [50]. Figure 3B depicts the steps involving hepatic lipid-induced insulin resistance. Few key events occur in the context of overnutrition, increased expression of hepatic suppressor of cytokine signaling-3 (SOCS3) and increased insulin resistance [51]. The increased portal flow of intra-abdominal fat-derived LCFA is associated with increased hepatic uptake and intracellular accumulation of LCFA, increase of lipotoxic substances such as ceramides, diacylglycerols (DAG) [52], and activation of the epsilon isoform of protein kinase C (PKCE) [53]. Hepatocellular DAG increased if the rates of DAG synthesis due to re-esterification of fatty acids and de novo lipogenesis are greater than the rates of mitochondrial long-chain CoA (fat) oxidation and rates of incorporation of DAG into triacylglycerides, or both combined events. Activated PKCE binds and inhibits the insulin receptor (IR-1) tyrosine kinase with decreased phosphorylation of the glycogen synthase kinase 3 (GSK3) ultimately leading to decreased glycogen synthesis. The decreased phosphorylation of forkhead box subgroup $\mathrm{O}$ (FOXO) will drive the FOXO translocation to the nucleus, and increased gene transcription of the gluconeogenic enzymes phosphoenolpyruvate carboxykinase (PEP-CK) and glucose-6phosphate (G6P) resulting in decreased insulin-mediated suppression of hepatic gluconeogenesis. The increase of IRS-1 and the downstream targets PI3K/Akt and sterol regulatory element-binding protein 1c (SREBP-1c) will further contribute to lipid accumulation and steatohepatitis [54]. Impaired mitochondrial and extra-mitochondrial oxidation [15] and production of reactive oxygen species (ROS) metabolites [55-57] also contribute to $\underline{\text { hepatocellular injury. }}$ 
Further events leading to hepatocyte death, liver fibrosis, and NASH are depicted in Figure 4

$[15,58]$. Excessive influx of LCFA in the liver upregulates several death receptors, i.e. DR5,

FAS, TRAIL-R2, TNFRSF1A (see legend) [59-61]. Excess intracellular FAs can result in

intrinsic endoplasmic reticulum stress, and mitochondrial dysfunction. Generation of ROS,

activation of JNK [62], caspase-2 pathway [63-65], and increased $\beta$-oxidation represent the

principal toxic pathways. Hepatocyte death follows the release of extracellular DAMPs and is

predisposing to inflammation and fibrosis upon accumulation of LCFA, intestinal endotoxins

and effect of DAMP on the TLR [66] of recruited macrophages (involving activation of

inflammasomes, pro-inflammatory cytokines, chemokines and inflammation $[67,681)$.

Activated stellate cells are sensitive to the ongoing oxidative stress and cholesterol

accumulation [66], and will promote myofibroblasts, collagen production and fibrosis [69-71].

T cells might also be involved in the progression of liver disease [50]. Endotoxins can originate

from gut microbiota and bacterial products of Gram- species[72]

Under such conditions, the balance between the extent of injurious events and the capacity to repair is highly impaired [73]. T-cells might also be involved in the progression of liver disease [50]. The involvement of the innate immune system suggests a role for toll-like receptors (TLRs) and the nucleotide-binding domain (NOD)-like receptor protein 3 (NLRP3) inflammasome, a cytosolic receptor. TLR4, in turn, leads to the activation of NF-kB, macrophage-derived chemokines, and activation of Kupffer cells. Injured hepatocytes release micro particles containing mtDNA, which will activate TLR9 pathways, due to their circular, prokaryote nature [74-76]. The recruitment of monocytes and macrophages to the liver will initiate the inflammatory cascades. The NLRP3 inflammasome responds to various noxious signals [DAMPs and pathogen-activated molecular patterns (PAMPs)] with recruitment of an apoptosis-associated speck-like protein (ASC) and activation of pro-caspase 1 . The ongoing mitochondrial dysfunction, lysosomal damage, and oxidative stress occurring during NASH could also activate the NLRP3 inflammasome. In addition, NF-KB regulates NLRP3 and prointerleukin-1 $\beta$ [54]. Fibrosis is the consequence of the ongoing liver damage, inflammatory cell 
death and reparative effort which involves activated transforming growth factor $\beta$ (TGF- $\beta$ )mediated activation of hepatic stellate cells with production of fibrous matrix [77]. Liver cancer is the ultimate consequence of such intense regenerative efforts.

The nuclear liver $X$ receptor $(L X R)$ also contributes to fat accumulation as transcriptional activator for lipogenesis via modulation of SREBP-1c and expression of fatty acid synthase, carbohydrate-responsive element-binding protein (ChREBP) and stearoyl-CoA desaturase-1 (SCD-1), all components of de-novo fatty acid biosynthesis. The intestinal farnesoid X nuclear receptor (FXR) upregulates SREBP-1c by enhancing ceramide synthesis, increasing de-novo lipogenesis and promoting the appearance of NAFLD [78]. Increased apoptosis occurs in NAFLD [54] while impaired autophagy contributes to accumulation of damaged cellular products in hepatocytes, inflammation and endoplasmic reticulum stress [79]. Finally, the prolonged disruption of physiological circadian rhythm in mice with fatty livers leads to the development of $\mathrm{NASH}$ by dysregulating the cross-talk between two nuclear hormone receptors, FXR and constitutive androstane receptor (CAR), resulting in suppression of FXR, accumulation of bile acids, bile acid-induced overactivation of CAR, liver injury, fibrosis, and even cancer. [요

Lipotoxicity encompasses the dysregulation of the intracellular lipid composition with accumulation of harmful lipids resulting in subcellular organelle dysfunction, including mitochondria, and leading to cell injury and even death. Generation of ceramides increases with proinflammatory cytokines, including IL-1 and IL-6, and contributes to inflammation via interaction with TNFa. In NASH, the increased expression of SREBP-2 leads to upregulation of HMG-CoA reductase, the rate limiting step of cholesterol synthesis, with a final accumulation of free cholesterol in mitochondria. Indeed, mitochondria are a well-established target of lipotoxicity and participate in the process of apoptosis and in generation of oxidative stressrelated products. In fact, in NASH hepatocytes, signals from death receptors converge on mitochondrial pathways of cell death, whereby caspase 8 cleaves Bid, resulting in release of citochrome c. In steatotic cells, FXR activation induced by bile acids alters different pathways 
involved in fatty acid metabolism: activation of peroxisome proliferator-activated receptor alpha (PPAR $\alpha$ ) with increased fatty acids oxidation, SREBP-1c inhibition and modulation of VLDL production.

\section{MITOCHONDRIAL DYSFUNCTION IN NAFLD/NASH}

Mitochondrial activities in hepatocytes encompass both metabolic pathways and signalling networks [81] with a viability depending on several factors including the integrity of mitochondrial DNA (mtDNA), membrane constituents, lipoprotein trafficking, pro- and antioxidant balance and metabolic demand and supply [르. Mitochondria are the most important sites for $\beta$-oxidation of fatty acids (FAs), whose main regulation depends on carnitine palmitoyltransferase 1 (CPT-1), the enzyme required for intra-mitochondrial transport of longchain FAs [ㅍ]. The progression of NAFLD to its more deleterious NASH form has been indicated as a type of mitochondrial disease $[\underline{13}, \underline{84]}$, a possibility occurring at an early stage in humans [85]. Mitochondrial defects stimulate ROS production, oxidative stress, and lead to impaired FA oxidation processes [86]. Activation of intracellular stress cascades or death receptor pathways in liver diseases can result in mitochondrial damage, by means of inner membrane permeabilization. Loss of impermeability of the inner mitochondrial membrane can lead to mitochondrial depolarization and disruption of the capacity to synthesize ATP, besides leading to the loss of antioxidant capacity [87-89].

On the other hand, an excessive production of ROS in mitochondria can be manifested by morphological changes, including cristae swelling [90], decreased ATP synthesis, and production of lipid peroxidation products malondialdehyde (MDA) and hydroxynonenal (HNE) [48]. Oxidative stress and inflammation are closely associated with elevated oxidative metabolism in obese individuals and this link may be exaggerated by increased work through anabolic pathways in fatty livers [91]. Disruptions of intracellular homeostatic processes and mitochondrial function activate both apoptotic signalling and necroptotic events [92]. Apoptosis is associated with changes in mitochondrial cardiolipin and phosphatidylcholine redox state 
and distribution. Apoptosis is also associated with increased probability of mitochondrial permeability transition pore (MPTP) opening as well as release of pro-apoptotic proteins from mitochondrial intermembrane space [93]. The final MPTP structure is still a matter of research. More recently, research has focused on the involvement of ATP synthase in pore formation i [94-97]. Beyond the release of cytochrome $\mathrm{c}$ and other pro-apoptotic factors into the cytosolic compartment, lysosomal damage, oxidative stress and MPTP opening seem to be involved in the activation of NLRP3 inflammasome and of the executioner caspase 3 which interacts with pro-caspases 6, 7 and 2 [98, 99]. Necroptosis appears to be a key event in NASH [100]. In this scenario, excessive production of ROS is responsible for the oxidative stress, lipid and protein oxidation and damage to mtDNA [101].

Nitrosative stress also acts as an additional mechanism for cell damage in NAFLD. Locally produced nitric oxide (NO) derivatives bind to proteins and thiols, resulting in enzyme inactivation and conformational changes in different membrane transporters [99]. NO exerts a controller activity on mitochondrial respiration and biogenesis [102]. Both ROS and NO may disrupt mitochondrial function by post-translational changes of the mitochondrial proteome which result in mitochondrial dysfunction. Indeed, mitochondrial proteomics points to defects in the assembly of multi-protein complexes, and resolution of highly hydrophobic proteins of the inner mitochondrial membrane [103]. A progressive deterioration of mitochondrial function, with decreased respiratory rates and ATP synthesis occurs in NAFLD. Simoes et al. [104] have reviewed the role of mitochondria in the development of NAFLD and its progression to NASH. Moreover, robust evidence suggests the existence of a relationships between human plasma branched-chain amino acids (BCAA) and insulin resistance, which is in line with the hypothesis that the mitochondrial modulation of the metabolism by BCAA result in a chronic metabolic overload from BCAA. These amino acids are essential to mediate efficient channeling of carbon substrates for oxidation through the mitochondrial tricarboxylic acid (TCA) cycle. Therefore, impairment of BCAA-mediated upregulation of the TCA cycle may significantly 
contribute to mitochondrial dysfunction in NAFLD [105]. Indeed, the link between insulin resistance and mitochondrial abnormalities has been widely documented [106].

Finally, mitochondrial genetics also seem to play a major role in NASH by active modulation of oxidative stress and controlling the efficiency of oxidative phosphorylation [107].

\section{THERAPEUTIC INTERVENTIONS ON MITOCHONDRIAL METABOLIC}

\section{PATHWAYS AND FUNCTION}

The presence of obesity and insulin resistance, and the degree of hepatic steatosis contribute to the severity of liver inflammation and fibrosis in NAFLD; by counteracting such participating factors, both liver histology and mitochondrial function can be improved [108, 109]. The most efficient treatments include weight loss and exercise [110], but adjunctive therapies are actively being investigated [ $\underline{58}, \underline{111]}$. Indeed, initial lifestyle interventions contribute to modulate the expression of the disease. Measures include reduction of body weight by dietary restriction or, in selected cases, by bariatric surgery (five to ten percent or even more of body weight, at a rate of $0.5-1.0 \mathrm{Kg}$ weekly, depending on the presence of overweight, obesity, biopsy-proven NASH and increased serum alanine aminotransferase, ALT). The program should also include regular physical activity (i.e. 30 min moderate exercise five times weekly or increase daily footsteps to 10,000 daily), since aerobic exercise improves skeletal muscle insulin sensitivity, a factor contributing to lower insulin resistance and liver steatosis [109, 112, 113]. The consumption of fructose-enriched beverages [114-116] and alcohol[117] must be limited. Intake of three to five cups of caffeinated coffee daily is $\underline{\text { recommended }[118] \text { since regular coffee consumption can significantly reduce the risk for }}$ hepatic fibrosis and cirrhosis [119] among NASH patients [120]. Because the fatty liverassociated lipotoxicity drives hepatocyte death and promotes $\mathrm{NASH}$, interventions aiming at preventing or treating NASH should firstly counteract the ongoing lipotoxicity. Ideally, the therapeutic agents should improve NAFLD/NASH by acting on intracellular metabolic pathways and the ongoing process of mitochondrial disruption [121]. 
Few agents may act also by targeting mitochondrial function. Peroxisome proliferatoractivated receptors (PPARs), which are ligand-activated transcription factors, regulate intracellular metabolic processes and shift hepatic metabolism toward lipid oxidation [122]. Thiazolidinediones are PPARy agonists and act as antidiabetic drug, and might play a role in this respect: pioglitazone improves NASH [123-127], but one of its side effects is weight gain [128]. Rosiglitazone is also effective in this regard [129-131]. Pioglitazone prevents the leakage of cytochrome c from mitochondria, stabilizes the mitochondrial transmembrane potential, inhibits ROS generation and activates the electron transport chain complexes I and III [132]. The European Association for the Study of the Liver (EASL) and the American Association for the Study of Liver Diseases (AASLD) [133,134] advise the use of pioglitazone to treat subjects with and without type 2 diabetes mellitus with biopsy-demonstrated NASH. Pioglitazone, in fact, improved liver histology in these patients [125]. However, it has no indication to treat NAFLD without biopsy-based proof of NASH [133, 134]. Other antidiabetic drugs, such as liraglutide (glucagon-like peptide 1 analogue) [135] and sitagliptin (dipeptidyl peptidase-4 inhibitor) $[136,137]$ may also be effective in NAFLD. In patients treated with elafibranor (an agonist of peroxisome proliferator-activated receptors $\alpha$ and $\delta$, involved in mechanisms improving insulin sensitivity, glucose homeostasis, lipid metabolism and inflammation), NASH resolved without worsening of fibrosis. Liver enzymes, glucose and lipid profiles, and systemic inflammatory markers also improved [138] (Figure 5).

Bile acids (BA) are soluble amphiphilic molecules, which represent the major lipid components of bile. Primary BA are synthetized from cholesterol in the liver and conjugated to glycine or taurine to increase their solubility. Upon secretion into bile, BA are concentrated in the gallbladder during fasting, expelled in the intestine in response to dietary fat and biotransformed to secondary BAs by the colonic gut microbiota (Figure 6). Both primary and secondary BA undergo reabsorption in the ileum and the colon, respectively, and then return to the liver, with minimal loss in the feces. Beside their digestive function, more lipophilic BA 
also play a role as signaling molecules in modulating epithelial cell proliferation, gene expression, and lipid and glucose metabolism by activation of the FXR and G-protein-coupled bile acid receptor-1 (GPBAR-1) in the liver, intestine, muscle and brown adipose tissue [139]. BA promote insulin sensitivity and decrease gluconeogenesis and circulating triglycerides [140]. In a randomized, multicenter double-blind placebo-controlled, parallel group clinical trial in USA, the synthetic variant of the natural primary BA chenodeoxycholic acid and potent FXR activator 6-ethylchenodeoxycholic acid (obeticholic acid, OCA, Intercept Pharmaceuticals) 25 $\mathrm{mg} /$ day orally for 72 weeks improved liver histology of $\mathrm{NASH}$ without worsening of fibrosis (Figure 7). In addition, serum alanine aminotransferase and aspartate aminotransferase concentrations decreased during OCA treatment [141]. The mechanism of action of OCA might imply the activation of FXR, with decreased hepatic lipogenesis because of down-regulation of the transcription factor SREBP1C and increased SIRT1 [142, 143].

Since mitochondrial and peroxisomal oxidation of fatty acids generate ROS, the use of antioxidant therapy represents one of the major strategies to counteract liver inflammation in NASH [144] (Figure 8). One recent study tested the efficacy of the antioxidant Tempol in mitigating liver injury associated to NASH. Tempol acts by selectively modulating the gut microbiota composition and metabolism under pro-steatotic conditions. Following the change in gut microbiota, liver histology showed a marked reduction in lipid droplets. Tempol also decreased liver weight and liver/body mass ratios in mice fed a steatogenic diet by interfering with the intestine-specific disruption of FXR [78]. In fact, intestinal FXR influences the ceramide/SREBP1C/CIDEA pathway and administration of ceramide attenuates the effects of the steatogenic diet that induces steatohepatitis. Therefore, inhibition of intestinal FXR is crucial for gut microbiome-mediated progression of NAFLD. The inhibition of intestinal FXR signaling also results in an improvement in mitochondrial function, repression of ceramide synthesis and reduction of its serum levels and, ultimately, in decreased hepatic steatosis [145]. Another antioxidant molecule, resveratrol, a polyphenol extract form red grapes and 
berries, exerts mitochondrial protectant properties [146] However, although promising, the possible health benefits of resveratrol were only demonstrated by an attenuation of liver fibrosis via the AKT and NF-KB pathway, but without effects on liver fat accumulation.

Other agents target antioxidant compounds into mitochondria. Mitoquinone (Mito-Q) and Mitovitamin E (MitoVit-E) represent a promising novel class of antioxidants. Both molecules contain a covalently attached lipophilic triphenylphosphonium (TPP) cationic moiety able to transport and concentrate antioxidant molecules within mitochondria [147-149]. Mito-Q improves metabolic syndrome in rats fed a high-fat diet for eight weeks [150] and the effect is associated with increased expression of cardiolipin synthase and cardiolipin levels in liver mitochondria [151]. In another study, Mito-Q prevented hypercholesterolemia, hypertriglyceridemia, mtDNA oxidative damage, hyperglycemia, and hepatic steatosis in experimental models of atherosclerosis and metabolic syndrome [152]. Low doses of Mito-Q and MitoVit-E protected cells against peroxide-induced oxidative damage and apoptosis, in contrast to what occurs with low doses of the untargeted antioxidants (e.g. Vit-E and ubiquinone). The protective effects of Mito-Q and MitoVit-E are likely mediated through the inhibition of cytochrome c release and caspase-3 activation. Furthermore, Mito-Q and MitoVitE reduced ROS-induced transferrin receptor-mediated iron uptake in mitochondria, lipid peroxidation, lipid peroxide-induced inactivation of complex I, and aconitase [153]. A phase II study in patients with chronic hepatitis $C$ demonstrated that Mito-Q decreased circulating aminotransferase levels; this effect may suggest reduced hepatic inflammation and necrosis in these patients [154].

Medicinal plants can be used as dietary supplements [155] and silymarin is extracted from milk thistle (Silybum marianum) with silybin as its major active compound. Silybin displays some hepatoprotective effects [156] and might improve insulin resistance, liver injury and liver enzymes in patients with NAFLD [157, 158]. The silybin-phospholipid complex containing vitamin E improved liver steatosis in NAFLD patients [159], and significantly lowered fat infiltration in the liver of rats fed a high fat diet, likely by modulating thioredoxin changes and 
the production of nitric oxide (NO) derivatives and by significantly lowering lipid peroxidation. Silybin also attenuated changes in mitochondrial respiratory complexes, with a major protective effect on Complex II subunit CII-30 [46]. Recently, we showed additional protective effects of silybin on rat hepatoma $\mathrm{FaO}$ cells mimicking a progressive model of liver steatosis [160]. Of note, silybin reduced excessive TG accumulation, changed the expression of transcription factors (PPARs, enzymes for mitochondrial, peroxisomal, and ER oxidations of FAs). Silybin also rescued the FA-induced mitochondrial dysfunction (size and function) and the apoptotic signals and oxidative stress, which resemble a condition of steatohepatitis [90]. Finally, the "mitotherapy", i.e., the exogenous intravenous injection of functional mitochondria from hepatoma cells has recently found to improve successfully the phenotype of liver steatosis induced by high-fat diet, by decreasing lipid content and restoring cellular redox balance. In brief, exogenous mitochondria were tagged with green-fluorescence protein (GFP) and were found in mouse liver, lungs, brain, muscle, and kidneys [161, 162]. This disruptive strategy results in attenuation of lipid deposits, prevention of cell injury, improved energy production with restored hepatocyte function. However, it is not clear how intact mitochondria enter the different cells and restore the cell metabolic activity [13]. Further research is evolving in this direction, especially concerning the nature of the administrated mitochondria with potential metabolic and proteomic differences vs. mitochondrial isolated from normal, nontumour-derived hepatocytes.

Finally, the role of several other agents is currently being investigated, i.e. Mgl-3196 (Madrigal Pharmaceuticals), GS-9674 (Gilead Sciences), NGM282 (NGM Bio), arachidyl amido cholanoic acid (Aramchol, Galmed Pharmaceuticals), and tropifexor (Novartis). However, the ultimate effect of such molecules on mitochondrial function is not defined and deserves further and specific investigations.

\section{SUMMARY}


Impairment of several intracellular metabolic pathways can have a role in the pathogenesis of $\mathrm{NASH}$. Lipotoxicity associated with glucotoxicity represent the most recent pathogenic view. Several new drugs and molecular targets appear promising; however, the results of recent clinical trials indicate that the complex pathogenesis of NASH is still the limiting step to reach an optimal pharmacological approach. Treatments may need to target some subcellular organelles that are fundamental in the pathogenic process, other than acting on genetic risk variants or on metabolic/environmental stressors. Ideally, disease-modifying factors may act both on mitochondrial function and energy supply and on regulators of lipid metabolism such as peroxisomes. In this view, the future research should focus its attention also by considering the potential role of microbiota and intestinal nuclear receptors. 


\section{REFERENCES}

[1] S. Bellentani, C. Tiribelli, Is it time to change NAFLD and NASH nomenclature?, The lancet. Gastroenterology \& hepatology 2(8) (2017) 547-548. doi: 10.1016/S2468-1253(17)30146-2

[2] V.W. Wong, W.K. Chan, S. Chitturi, Y. Chawla, Y.Y. Dan, A. Duseja, J. Fan, K.L. Goh, M. Hamaguchi, E. Hashimoto, S.U. Kim, L.A. Lesmana, Y.C. Lin, C.J. Liu, Y.H. Ni, J. Sollano, S.K. Wong, G.L. Wong, H.L. Chan, G. Farrell, Asia-Pacific Working Party on Non-alcoholic Fatty Liver Disease guidelines 2017Part 1: Definition, risk factors and assessment, J Gastroenterol Hepatol 33(1) (2018) 70-85. doi: $\underline{10.1111 / \text { igh. } 13857}$

[3] A. Lonardo, F. Nascimbeni, A. Mantovani, G. Targher, Hypertension, diabetes, atherosclerosis and NASH: Cause or consequence?, Journal of hepatology 68(2) (2018) 335-352. doi: 10.1016/.j.jhep.2017.09.021

[4] M. Krawczyk, P. Portincasa, F. Lammert, PNPLA3-associated steatohepatitis: toward a gene-based classification of fatty liver disease, Seminars in liver disease 33(4) (2013) 369-79. doi: $\underline{10.1055 / \mathrm{s}-0033-}$ $\underline{1358525}$

[5] Z. Younossi, Q.M. Anstee, M. Marietti, T. Hardy, L. Henry, M. Eslam, J. George, E. Bugianesi, Global burden of NAFLD and NASH: trends, predictions, risk factors and prevention, Nature reviews. Gastroenterology \& hepatology 15(1) (2018) 11-20. doi: $\underline{10.1038 / \text { nrgastro.2017.109 }}$

[6] A.L. Fracanzani, L. Valenti, E. Bugianesi, E. Vanni, A. Grieco, L. Miele, D. Consonni, E. Fatta, R. Lombardi, G. Marchesini, S. Fargion, Risk of nonalcoholic steatohepatitis and fibrosis in patients with nonalcoholic fatty liver disease and low visceral adiposity, Journal of hepatology 54(6) (2011) 1244-9. doi: $\underline{10.1016 / \text { i.jhep.2010.09.037 }}$

[7] S. Krahenbuhl, Alterations in mitochondrial function and morphology in chronic liver disease: pathogenesis and potential for therapeutic intervention, Pharmacol Ther 60(1) (1993) 1-38. doi:

[8] G.E. Kass, Mitochondrial involvement in drug-induced hepatic injury, Chem Biol Interact 163(1-2) (2006) 145-59. doi: $\underline{10.1016 / \text { i.cbi.2006.06.007 }}$

[9] S.H. Caldwell, L.A. de Freitas, S.H. Park, M.L. Moreno, J.A. Redick, C.A. Davis, B.J. Sisson, J.T. Patrie, H. Cotrim, C.K. Argo, A. Al-Osaimi, Intramitochondrial crystalline inclusions in nonalcoholic steatohepatitis, Hepatology 49(6) (2009) 1888-95. doi: 10.1002/hep.22851

[10] S.H. Caldwell, C.Y. Chang, R.K. Nakamoto, L. Krugner-Higby, Mitochondria in nonalcoholic fatty liver disease, Clinics in liver disease 8(3) (2004) 595-617, x. doi: $\underline{10.1016 / j . c l d .2004 .04 .009}$

[11] F. Ge, H.t. Lobdell, S. Zhou, C. Hu, P.D. Berk, Digital analysis of hepatic sections in mice accurately quantitates triglycerides and selected properties of lipid droplets, Exp Biol Med (Maywood) 235(11) (2010) 1282-6. doi: 10.1258/ebm.2010.010095

[12] F. Ge, S. Zhou, C. Hu, H. Lobdell, P.D. Berk, Insulin-and leptin-regulated fatty acid uptake plays a key causal role in hepatic steatosis in mice with intact leptin signaling but not in ob/ob or $\mathrm{db} / \mathrm{db}$ mice, American Journal of Physiology-Gastrointestinal and Liver Physiology 299(4) (2010) G855-G866. doi:

[13] D. Pessayre, B. Fromenty, NASH: a mitochondrial disease, Journal of hepatology 42(6) (2005) 92840. doi: $10.1016 /$ j.jhep.2005.03.004

[14] G. Calamita, P. Portincasa, Present and future therapeutic strategies in non-alcoholic fatty liver disease, Expert Opin Ther Targets 11(9) (2007) 1231-49. doi: 10.1517/14728222.11.9.1231

[15] P.D. Berk, E.C. Verna, Nonalcoholic Fatty Liver Disease: Lipids and Insulin Resistance, Clinics in liver disease 20(2) (2016) 245-62. doi: 10.1016/..cld.2015.10.007

[16] H. Doege, A. Stahl, Protein-mediated fatty acid uptake: novel insights from in vivo models, Physiology (Bethesda) 21(4) (2006) 259-68. doi: 10.1152/physiol.00014.2006 
[17] F. Ge, J.L. Walewski, M.H. Torghabeh, H.t. Lobdell, C. Hu, S. Zhou, G. Dakin, A. Pomp, M. Bessler, B. Schrope, A. Ude-Welcome, W.B. Inabnet, T. Feng, E. Carras-Terzian, D. Anglade, F.E. Ebel, P.D. Berk, Facilitated long chain fatty acid uptake by adipocytes remains upregulated relative to BMI for more than a year after major bariatric surgical weight loss, Obesity 24(1) (2016) 113-22. doi: $\underline{10.1002 / o b y .21249}$

[18] F. Ge, C. Hu, E. Hyodo, K. Arai, S. Zhou, H.t. Lobdell, J.L. Walewski, S. Homma, P.D. Berk, Cardiomyocyte triglyceride accumulation and reduced ventricular function in mice with obesity reflect increased long chain Fatty Acid uptake and de novo Fatty Acid synthesis, Journal of obesity 2012 (2012) 205648. doi: $\underline{10.1155 / 2012 / 205648}$

[19] P.D. Berk, S.L. Zhou, C.L. Kiang, D. Stump, M. Bradbury, L.M. Isola, Uptake of long chain free fatty acids is selectively up-regulated in adipocytes of Zucker rats with genetic obesity and non-insulindependent diabetes mellitus, The Journal of biological chemistry 272(13) (1997) 8830-5. doi:

[20] X. Fan, M.W. Bradbury, P.D. Berk, Leptin and insulin modulate nutrient partitioning and weight loss in ob/ob mice through regulation of long-chain fatty acid uptake by adipocytes, J Nutr 133(9) (2003) 2707-15. doi: $\underline{10.1093 / \mathrm{in} / 133.9 .2707}$

[21] J. Jou, S.S. Choi, A.M. Diehl, Mechanisms of disease progression in nonalcoholic fatty liver disease, Seminars in liver disease, (C) Thieme Medical Publishers, 2008, pp. 370-379.

[22] O. Petrescu, X. Fan, P. Gentileschi, S. Hossain, M. Bradbury, M. Gagner, P.D. Berk, Long-chain fatty acid uptake is upregulated in omental adipocytes from patients undergoing bariatric surgery for obesity, International journal of obesity 29(2) (2005) 196-203. doi: 10.1038/sj.ijo.0802868

[23] A. Stahl, R.E. Gimeno, L.A. Tartaglia, H.F. Lodish, Fatty acid transport proteins: a current view of a growing family, Trends in endocrinology and metabolism: TEM 12(6) (2001) 266-73. doi:

[24] J.E. Schaffer, H.F. Lodish, Expression cloning and characterization of a novel adipocyte long chain fatty acid transport protein, Cell 79(3) (1994) 427-36. doi:

[25] M. Digel, R. Ehehalt, W. Stremmel, J. Fullekrug, Acyl-CoA synthetases: fatty acid uptake and metabolic channeling, Molecular and cellular biochemistry 326(1-2) (2009) 23-8. doi: 10.1007/s11010$\underline{008-0003-3}$

[26] J. Pohl, A. Ring, W. Stremmel, Uptake of long-chain fatty acids in HepG2 cells involves caveolae: analysis of a novel pathway, Journal of lipid research 43(9) (2002) 1390-9. doi:

[27] H. Mitsuyoshi, K. Yasui, Y. Harano, M. Endo, K. Tsuji, M. Minami, Y. Itoh, T. Okanoue, T. Yoshikawa, Analysis of hepatic genes involved in the metabolism of fatty acids and iron in nonalcoholic fatty liver disease, Hepatology research : the official journal of the Japan Society of Hepatology 39(4) (2009) 366-73. doi: 10.1111/j.1872-034X.2008.00464.X

[28] V.T. Samuel, Z.-X. Liu, A. Wang, S.A. Beddow, J.G. Geisler, M. Kahn, X.-m. Zhang, B.P. Monia, S. Bhanot, G.I. Shulman, Inhibition of protein kinase $C \varepsilon$ prevents hepatic insulin resistance in nonalcoholic fatty liver disease, The Journal of clinical investigation 117(3) (2007) 739-745. doi:

[29] J.P. Kampf, D. Parmley, A.M. Kleinfeld, Free fatty acid transport across adipocytes is mediated by an unknown membrane protein pump, American journal of physiology. Endocrinology and metabolism 293(5) (2007) E1207-14. doi: 10.1152/ajpendo.00259.2007

[30] J.P. Kampf, A.M. Kleinfeld, Is membrane transport of FFA mediated by lipid, protein, or both? An unknown protein mediates free fatty acid transport across the adipocyte plasma membrane, Physiology (Bethesda) 22 (2007) 7-14. doi: 10.1152/physiol.00011.2006

[31] W. Stremmel, G. Strohmeyer, F. Borchard, S. Kochwa, P.D. Berk, Isolation and partial characterization of a fatty acid binding protein in rat liver plasma membranes, Proceedings of the National Academy of Sciences of the United States of America 82(1) (1985) 4-8. doi: 
[32] P.D. Berk, H. Wada, Y. Horio, B.J. Potter, D. Sorrentino, S.L. Zhou, L.M. Isola, D. Stump, C.L. Kiang, S. Thung, Plasma membrane fatty acid-binding protein and mitochondrial glutamic-oxaloacetic transaminase of rat liver are related, Proceedings of the National Academy of Sciences of the United States of America 87(9) (1990) 3484-8. doi:

[33] M.W. Bradbury, D. Stump, F. Guarnieri, P.D. Berk, Molecular modeling and functional confirmation of a predicted fatty acid binding site of mitochondrial aspartate aminotransferase, J Mol Biol 412(3) (2011) 412-22. doi: $10.1016 /$ j.jmb.2011.07.034

[34] N.A. Abumrad, M.R. el-Maghrabi, E.Z. Amri, E. Lopez, P.A. Grimaldi, Cloning of a rat adipocyte membrane protein implicated in binding or transport of long-chain fatty acids that is induced during preadipocyte differentiation. Homology with human CD36, The Journal of biological chemistry 268(24) (1993) 17665-8. doi:

[35] B.L. Trigatti, R.G. Anderson, G.E. Gerber, Identification of caveolin-1 as a fatty acid binding protein, Biochemical and biophysical research communications 255(1) (1999) 34-9. doi: $\underline{10.1006 / \mathrm{bbrc} .1998 .0123}$

[36] K.L. Donnelly, C.I. Smith, S.J. Schwarzenberg, J. Jessurun, M.D. Boldt, E.J. Parks, Sources of fatty acids stored in liver and secreted via lipoproteins in patients with nonalcoholic fatty liver disease, The Journal of clinical investigation 115(5) (2005) 1343-51. doi: $\underline{10.1172 / \mathrm{JCl} 23621}$

[37] J.E. Lambert, M.A. Ramos-Roman, J.D. Browning, E.J. Parks, Increased De Novo Lipogenesis Is a Distinct Characteristic of Individuals With Nonalcoholic Fatty Liver Disease, Gastroenterology 146(3) (2014) 726-735. doi: 10.1053/j.gastro.2013.11.049

[38] H.L. Kammoun, H. Chabanon, I. Hainault, S. Luquet, C. Magnan, T. Koike, P. Ferre, F. Foufelle, GRP78 expression inhibits insulin and ER stress-induced SREBP-1C activation and reduces hepatic steatosis in mice, The Journal of clinical investigation 119(5) (2009) 1201-15. doi: $\underline{10.1172 / \mathrm{JCl} 37007}$

[39] B. Schnabl, D.A. Brenner, Interactions Between the Intestinal Microbiome and Liver Diseases, Gastroenterology 146(6) (2014) 1513-1524. doi: 10.1053/i.gastro.2014.01.020

[40] G.D. Wu, J. Chen, C. Hoffmann, K. Bittinger, Y.Y. Chen, S.A. Keilbaugh, M. Bewtra, D. Knights, W.A. Walters, R. Knight, R. Sinha, E. Gilroy, K. Gupta, R. Baldassano, L. Nessel, H. Li, F.D. Bushman, J.D. Lewis, Linking long-term dietary patterns with gut microbial enterotypes, Science 334(6052) (2011) 105-8. doi: $\underline{10.1126 / \text { science. } 1208344}$

[41] L. Miele, V. Valenza, G. La Torre, M. Montalto, G. Cammarota, R. Ricci, R. Masciana, A. Forgione, M.L. Gabrieli, G. Perotti, F.M. Vecchio, G. Rapaccini, G. Gasbarrini, C.P. Day, A. Grieco, Increased intestinal permeability and tight junction alterations in nonalcoholic fatty liver disease, Hepatology $49(6)$ (2009) 1877-87. doi: $\underline{10.1002 / h e p .22848}$

[42] M. Krawczyk, L. Bonfrate, P. Portincasa, Nonalcoholic fatty liver disease, Best practice \& research. Clinical gastroenterology 24(5) (2010) 695-708. doi: 10.1016/j.bpg.2010.08.005

[43] E. Altomare, I. Grattagliano, D. Didonna, A. Gentile, G. Vendemiale, Gastric and intestinal ethanol toxicity in the rat. Effect on glutathione level and role of alcohol and acetaldehyde metabolisms, Ital J Gastroenterol Hepatol 30(1) (1998) 82-90. doi:

[44] I. Grattagliano, P. Caraceni, G. Calamita, D. Ferri, I. Gargano, G. Palasciano, P. Portincasa, Severe liver steatosis correlates with nitrosative and oxidative stress in rats, European journal of clinical investigation 38(7) (2008) 523-30. doi: 10.1111/j.1365-2362.2008.01963.x

[45] I. Grattagliano, P. Caraceni, P. Portincasa, M. Domenicali, V.O. Palmieri, F. Trevisani, M. Bernardi, G. Palasciano, Adaptation of subcellular glutathione detoxification system to stress conditions in cholinedeficient diet induced rat fatty liver, Cell biology and toxicology 19(6) (2003) 355-66. doi:

[46] I. Grattagliano, C.V. Diogo, M. Mastrodonato, O. de Bari, M. Persichella, D.Q. Wang, A. Liquori, D. Ferri, M.R. Carratu, P.J. Oliveira, P. Portincasa, A silybin-phospholipids complex counteracts rat fatty 
liver degeneration and mitochondrial oxidative changes, World journal of gastroenterology : WJG 19(20) (2013) 3007-17. doi: 10.3748/wjg.v19.i20.3007

[47] I. Grattagliano, G. Vendemiale, P. Caraceni, M. Domenicali, B. Nardo, A. Cavallari, F. Trevisani, M. Bernardi, E. Altomare, Starvation impairs antioxidant defense in fatty livers of rats fed a choline-deficient diet, J Nutr 130(9) (2000) 2131-6. doi: $\underline{10.1093 / \mathrm{jn} / 130.9 .2131}$

[48] G. Petrosillo, P. Portincasa, I. Grattagliano, G. Casanova, M. Matera, F.M. Ruggiero, D. Ferri, G. Paradies, Mitochondrial dysfunction in rat with nonalcoholic fatty liver Involvement of complex I, reactive oxygen species and cardiolipin, Biochimica et biophysica acta 1767(10) (2007) 1260-7. doi: 10.1016/j.bbabio.2007.07.011

[49] G. Bedogni, L. Miglioli, F. Masutti, C. Tiribelli, G. Marchesini, S. Bellentani, Prevalence of and risk factors for nonalcoholic fatty liver disease: the Dionysos nutrition and liver study, Hepatology 42(1) (2005) 44-52. doi: 10.1002/hep.20734

[50] P. Portincasa, D.Q.H. Wang, Nonalcoholic fatty liver and gallstone disease, in: D.Q.H. Wang, P. Portincasa (Eds.), Gallstones. Recent advances in epidemiology, pathogenesis, diagnosis and management, Nova Science Publisher Inc., New York, 2017, pp. 387-414.

[51] E. Fabbrini, S. Sullivan, S. Klein, Obesity and nonalcoholic fatty liver disease: biochemical, metabolic, and clinical implications, Hepatology 51(2) (2010) 679-89. doi: 10.1002/hep.23280

[52] J.E. Schaffer, Lipotoxicity: when tissues overeat, Current opinion in lipidology 14(3) (2003) 281-7. doi: $\underline{10.1097 / 01 . m o l} .0000073508 .41685 .7 f$

[53] C. Postic, J. Girard, Contribution of de novo fatty acid synthesis to hepatic steatosis and insulin resistance: lessons from genetically engineered mice, The Journal of clinical investigation 118(3) (2008) 829-38. doi: $10.1172 / \mathrm{JCl} 34275$

[54] V.W. Wong, S. Chitturi, G.L. Wong, J. Yu, H.L. Chan, G.C. Farrell, Pathogenesis and novel treatment options for non-alcoholic steatohepatitis, The lancet. Gastroenterology \& hepatology 1(1) (2016) 56-67. doi: $\underline{10.1016 / S 2468-1253(16) 30011-5}$

[55] R.H. Unger, L. Orci, Diseases of liporegulation: new perspective on obesity and related disorders, FASEB J 15(2) (2001) 312-21. doi: 10.1096/fj.00-0590

[56] R.H. Unger, Minireview: weapons of lean body mass destruction: the role of ectopic lipids in the metabolic syndrome, Endocrinology 144(12) (2003) 5159-65. doi: 10.1210/en.2003-0870

[57] G.I. Shulman, Ectopic fat in insulin resistance, dyslipidemia, and cardiometabolic disease, The New England journal of medicine 371(12) (2014) 1131-41. doi: 10.1056/NEJMra1011035

[58] F. Marra, G. Svegliati-Baroni, Lipotoxicity and the gut-liver axis in NASH pathogenesis, Journal of hepatology 68(2) (2018) 280-295. doi: 10.1016/i.jhep.2017.11.014

[59] S. Inokuchi-Shimizu, E.J. Park, Y.S. Roh, L. Yang, B. Zhang, J. Song, S. Liang, M. Pimienta, K. Taniguchi, X. Wu, K. Asahina, W. Lagakos, M.R. Mackey, S. Akira, M.H. Ellisman, D.D. Sears, J.M. Olefsky, M. Karin, D.A. Brenner, E. Seki, TAK1-mediated autophagy and fatty acid oxidation prevent hepatosteatosis and tumorigenesis, The Journal of clinical investigation 124(8) (2014) 3566-78. doi: $\underline{10.1172 / \mathrm{JCl} 74068}$

[60] J. Gautheron, M. Vucur, F. Reisinger, D.V. Cardenas, C. Roderburg, C. Koppe, K. Kreggenwinkel, A.T. Schneider, M. Bartneck, U.P. Neumann, A positive feedback loop between RIP3 and JNK controls non-alcoholic steatohepatitis, EMBO molecular medicine 6(8) (2014) 1062-1074. doi:

[61] C. Koliaki, J. Szendroedi, K. Kaul, T. Jelenik, P. Nowotny, F. Jankowiak, C. Herder, M. Carstensen, M. Krausch, W.T. Knoefel, M. Schlensak, M. Roden, Adaptation of hepatic mitochondrial function in humans with non-alcoholic fatty liver is lost in steatohepatitis, Cell metabolism 21(5) (2015) 739-46. doi: 10.1016/i.cmet.2015.04.004 
[62] M.V. Machado, G.A. Michelotti, A. Pereira Tde, J. Boursier, L. Kruger, M. Swiderska-Syn, G. Karaca, G. Xie, C.D. Guy, B. Bohinc, K.R. Lindblom, E. Johnson, S. Kornbluth, A.M. Diehl, Reduced lipoapoptosis, hedgehog pathway activation and fibrosis in caspase-2 deficient mice with non-alcoholic steatohepatitis, Gut 64(7) (2015) 1148-57. doi: 10.1136/gutinl-2014-307362

[63] E.S. Johnson, K.R. Lindblom, A. Robeson, R.D. Stevens, O.R. Ilkayeva, C.B. Newgard, S. Kornbluth, J.L. Andersen, Metabolomic profiling reveals a role for caspase-2 in lipoapoptosis, The Journal of biological chemistry $288(20)$ (2013) 14463-75. doi: $10.1074 /$ jbc.M112.437210

[64] J.P. Upton, K. Austgen, M. Nishino, K.M. Coakley, A. Hagen, D. Han, F.R. Papa, S.A. Oakes, Caspase-2 cleavage of BID is a critical apoptotic signal downstream of endoplasmic reticulum stress, Molecular and cellular biology 28(12) (2008) 3943-3951. doi: $\underline{10.1128 / \mathrm{Mcb} .00013-08}$

[65] Y.S. Roh, E. Seki, Toll-like receptors in alcoholic liver disease, non-alcoholic steatohepatitis and carcinogenesis, J Gastroenterol Hepatol 28 Suppl 1(S1) (2013) 38-42. doi: 10.1111/jgh.12019

[66] A. Wehr, C. Baeck, F. Ulmer, N. Gassler, K. Hittatiya, T. Luedde, U.P. Neumann, C. Trautwein, F. Tacke, Pharmacological inhibition of the chemokine CXCL16 diminishes liver macrophage infiltration and steatohepatitis in chronic hepatic injury, PloS one 9(11) (2014) e112327. doi: 10.1371/journal.pone.0112327

[67] A. Leroux, G. Ferrere, V. Godie, F. Cailleux, M.-L. Renoud, F. Gaudin, S. Naveau, S. Prévot, S. Makhzami, G. Perlemuter, Toxic lipids stored by Kupffer cells correlates with their pro-inflammatory phenotype at an early stage of steatohepatitis, Journal of hepatology 57(1) (2012) 141-149. doi:

[68] E.M. Brunt, V.W. Wong, V. Nobili, C.P. Day, S. Sookoian, J.J. Maher, E. Bugianesi, C.B. Sirlin, B.A. Neuschwander-Tetri, M.E. Rinella, Nonalcoholic fatty liver disease, Nat Rev Dis Primers 1 (2015) 15080. doi: $\underline{10.1038 / \mathrm{nrdp} .2015 .80}$

[69] M.C. Wallace, S.L. Friedman, D.A. Mann, Emerging and disease-specific mechanisms of hepatic stellate cell activation, Seminars in liver disease, 2015, pp. 107-118.

[70] E. Seki, S. De Minicis, C.H. Osterreicher, J. Kluwe, Y. Osawa, D.A. Brenner, R.F. Schwabe, TLR4 enhances TGF-beta signaling and hepatic fibrosis, Nature medicine 13(11) (2007) 1324-32. doi: $\underline{10.1038 / \mathrm{nm} 1663}$

[71] K. Tomita, T. Teratani, T. Suzuki, M. Shimizu, H. Sato, K. Narimatsu, Y. Okada, C. Kurihara, R. Irie, H. Yokoyama, K. Shimamura, S. Usui, H. Ebinuma, H. Saito, C. Watanabe, S. Komoto, A. Kawaguchi, S. Nagao, K. Sugiyama, R. Hokari, T. Kanai, S. Miura, T. Hibi, Free cholesterol accumulation in hepatic stellate cells: mechanism of liver fibrosis aggravation in nonalcoholic steatohepatitis in mice, Hepatology 59(1) (2014) 154-69. doi: 10.1002/hep.26604

[72] A.M. Diehl, C. Day, Cause, Pathogenesis, and Treatment of Nonalcoholic Steatohepatitis, The New England journal of medicine 377(21) (2017) 2063-2072. doi: 10.1056/NEJMra1503519

[73] K. Wegermann, A.M. Diehl, C.A. Moylan, Disease pathways and molecular mechanisms of nonalcoholic steatohepatitis, Clinical Liver Disease 11(4) (2018) 87-91. doi: $\underline{10.1002 / \text { cld.709 }}$

[74] P. Handa, A. Vemulakonda, K.V. Kowdley, M. Uribe, N. Mendez-Sanchez, Mitochondrial DNA from hepatocytes as a ligand for TLR9: Drivers of nonalcoholic steatohepatitis?, World journal of gastroenterology : WJG 22(31) (2016) 6965-71. doi: 10.3748/wjg.v22.i31.6965

[75] M.E. Inzaugarat, A. Wree, A.E. Feldstein, Hepatocyte mitochondrial DNA released in microparticles and toll-like receptor 9 activation: A link between lipotoxicity and inflammation during nonalcoholic steatohepatitis, Hepatology 64(2) (2016) 669-71. doi: $\underline{\text { 10.1002/hep.28666 }}$

[76] I. Garcia-Martinez, N. Santoro, Y. Chen, R. Hoque, X. Ouyang, S. Caprio, M.J. Shlomchik, R.L. Coffman, A. Candia, W.Z. Mehal, Hepatocyte mitochondrial DNA drives nonalcoholic steatohepatitis by activation of TLR9, The Journal of clinical investigation 126(3) (2016) 859-64. doi: $10.1172 / \mathrm{JCl} 83885$ 
[77] A. Suzuki, A.M. Diehl, Nonalcoholic Steatohepatitis, Annual review of medicine 68 (2017) 85-98. doi: $\underline{\text { 10.1146/annurev-med-051215-031109 }}$

[78] C. Jiang, C. Xie, F. Li, L. Zhang, R.G. Nichols, K.W. Krausz, J. Cai, Y. Qi, Z.Z. Fang, S. Takahashi, N. Tanaka, D. Desai, S.G. Amin, I. Albert, A.D. Patterson, F.J. Gonzalez, Intestinal farnesoid X receptor signaling promotes nonalcoholic fatty liver disease, The Journal of clinical investigation 125(1) (2015) 386-402. doi: $\underline{10.1172 / \mathrm{JCl} 76738}$

[79] Y. Fukuo, S. Yamashina, H. Sonoue, A. Arakawa, E. Nakadera, T. Aoyama, A. Uchiyama, K. Kon, K. Ikejima, S. Watanabe, Abnormality of autophagic function and cathepsin expression in the liver from patients with non-alcoholic fatty liver disease, Hepatology research : the official journal of the Japan Society of Hepatology 44(9) (2014) 1026-36. doi: 10.1111/hepr.12282

[80] N.M. Kettner, H. Voicu, M.J. Finegold, C. Coarfa, A. Sreekumar, N. Putluri, C.A. Katchy, C. Lee, D.D. Moore, L. Fu, Circadian Homeostasis of Liver Metabolism Suppresses Hepatocarcinogenesis, Cancer cell 30(6) (2016) 909-924. doi: 10.1016/j.ccell.2016.10.007

[81] F. Guerrieri, C. Nicoletti, E. Adorisio, G. Caraccio, P. Leonetti, F. Zanotti, P. Cantatore, Correlation between decreased expression of mitochondrial FOF1-ATP synthase and low regenerating capability of the liver after partial hepatectomy in hypothyroid rats, Journal of Bioenergetics and Biomembranes 32(2) (2000) 183-191. doi: Doi 10.1023/A:1005564031119

[82] I. Grattagliano, O. De Bari, D. Di Palo, F. Montecucco, F. Carbone, P. Oliveira, D.Q.H. Wang, P. Portincasa, Mitochondria in liver diseases, in: P. Oliveira (Ed.), Mitochondrial Biology and Experimental Therapeutics, Springer Nature, Cham, Switzerland, 2018, pp. 91-126.

[83] G. Serviddio, A.M. Giudetti, F. Bellanti, P. Priore, T. Rollo, R. Tamborra, L. Siculella, G. Vendemiale, E. Altomare, G.V. Gnoni, Oxidation of hepatic carnitine palmitoyl transferase-I (CPT-I) impairs fatty acid beta-oxidation in rats fed a methionine-choline deficient diet, PloS one 6(9) (2011) e24084. doi: 10.1371/journal.pone.0024084

[84] D. Pessayre, A. Berson, B. Fromenty, A. Mansouri, Mitochondria in steatohepatitis, Seminars in liver disease 21(1) (2001) 57-69. doi:

[85] P. Portincasa, I. Grattagliano, B.H. Lauterburg, V.O. Palmieri, G. Palasciano, F. Stellaard, Liver breath tests non-invasively predict higher stages of non-alcoholic steatohepatitis, Clin Sci (Lond) 111(2) (2006) 135-43. doi: $10.1042 / C S 20050346$

[86] K. Begriche, J. Massart, M.A. Robin, A. Borgne-Sanchez, B. Fromenty, Drug-induced toxicity on mitochondria and lipid metabolism: mechanistic diversity and deleterious consequences for the liver, Journal of hepatology 54(4) (2011) 773-94. doi: 10.1016/i.jhep.2010.11.006

[87] X. Yin, F. Zheng, Q. Pan, S. Zhang, D. Yu, Z. Xu, H. Li, Glucose fluctuation increased hepatocyte apoptosis under lipotoxicity and the involvement of mitochondrial permeability transition opening, Journal of molecular endocrinology 55(3) (2015) 169-81. doi: 10.1530/JME-15-0101

[88] C.D.C. Navarro, T.R. Figueira, A. Francisco, G.A. Dal'Bo, J.A. Ronchi, J.C. Rovani, C.A.F. Escanhoela, H.C.F. Oliveira, R.F. Castilho, A.E. Vercesi, Redox imbalance due to the loss of mitochondrial $N A D(P)$-transhydrogenase markedly aggravates high fat diet-induced fatty liver disease in mice, Free radical biology \& medicine 113 (2017) 190-202. doi: 10.1016/.jfreeradbiomed.2017.09.026

[89] A.L. King, T.M. Swain, Z. Mao, U.S. Udoh, C.R. Oliva, A.M. Betancourt, C.E. Griguer, D.R. Crowe, M. Lesort, S.M. Bailey, Involvement of the mitochondrial permeability transition pore in chronic ethanolmediated liver injury in mice, American journal of physiology. Gastrointestinal and liver physiology 306(4) (2014) G265-77. doi: 10.1152/ajpgi.00278.2013

[90] G. Vecchione, E. Grasselli, F. Cioffi, F. Baldini, P.J. Oliveira, V.A. Sardao, K. Cortese, A. Lanni, A. Voci, P. Portincasa, L. Vergani, The Nutraceutic Silybin Counteracts Excess Lipid Accumulation and Ongoing Oxidative Stress in an In Vitro Model of Non-Alcoholic Fatty Liver Disease Progression, Frontiers in nutrition 4 (2017) 42. doi: $\underline{10.3389 / \text { fnut.2017.00042 }}$ 
[91] S. Satapati, B. Kucejova, J.A. Duarte, J.A. Fletcher, L. Reynolds, N.E. Sunny, T. He, L.A. Nair, K.A. Livingston, X. Fu, M.E. Merritt, A.D. Sherry, C.R. Malloy, J.M. Shelton, J. Lambert, E.J. Parks, I. Corbin, M.A. Magnuson, J.D. Browning, S.C. Burgess, Mitochondrial metabolism mediates oxidative stress and inflammation in fatty liver, The Journal of clinical investigation 125(12) (2015) 4447-62. doi: $\underline{10.1172 / \mathrm{JCl} 82204}$

[92] V.E. Kagan, H.A. Bayir, N.A. Belikova, O. Kapralov, Y.Y. Tyurina, V.A. Tyurin, J. Jiang, D.A. Stoyanovsky, P. Wipf, P.M. Kochanek, J.S. Greenberger, B. Pitt, A.A. Shvedova, G. Borisenko, Cytochrome c/cardiolipin relations in mitochondria: a kiss of death, Free radical biology \& medicine 46(11) (2009) 1439-53. doi: 10.1016/.j.freeradbiomed.2009.03.004

[93] D. Haouzi, M. Lekehal, A. Moreau, C. Moulis, G. Feldmann, M.A. Robin, P. Letteron, D. Fau, D. Pessayre, Cytochrome P450-generated reactive metabolites cause mitochondrial permeability transition, caspase activation, and apoptosis in rat hepatocytes, Hepatology 32(2) (2000) 303-11. doi: 10.1053/ihep.2000.9034

[94] M. Bonora, C. Morganti, G. Morciano, G. Pedriali, M. Lebiedzinska-Arciszewska, G. Aquila, C. Giorgi, P. Rizzo, G. Campo, R. Ferrari, G. Kroemer, M.R. Wieckowski, L. Galluzzi, P. Pinton, Mitochondrial permeability transition involves dissociation of F1FO ATP synthase dimers and C-ring conformation, Embo Rep 18(7) (2017) 1077-1089. doi: 10.15252/embr.201643602

[95] P.A. Elustondo, M. Nichols, A. Negoda, A. Thirumaran, E. Zakharian, G.S. Robertson, E.V. Pavlov, Mitochondrial permeability transition pore induction is linked to formation of the complex of ATPase Csubunit, polyhydroxybutyrate and inorganic polyphosphate, Cell Death Discov 2 (2016) 16070. doi: 10.1038/cddiscovery.2016.70

[96] J. He, J. Carroll, S. Ding, I.M. Fearnley, J.E. Walker, Permeability transition in human mitochondria persists in the absence of peripheral stalk subunits of ATP synthase, Proceedings of the National Academy of Sciences of the United States of America 114(34) (2017) 9086-9091. doi: $\underline{10.1073 / \text { pnas. } 1711201114}$

[97] J. He, H.C. Ford, J. Carroll, S. Ding, I.M. Fearnley, J.E. Walker, Persistence of the mitochondrial permeability transition in the absence of subunit $\mathrm{c}$ of human ATP synthase, Proceedings of the National Academy of Sciences of the United States of America 114(13) (2017) 3409-3414. doi: $\underline{10.1073 / \text { pnas. } 1702357114}$

[98] L. Papucci, L. Formigli, N. Schiavone, A. Tani, M. Donnini, A. Lapucci, F. Perna, A. Tempestini, E. Witort, M. Morganti, D. Nosi, G.E. Orlandini, S. Zecchi Orlandini, S. Capaccioli, Apoptosis shifts to necrosis via intermediate types of cell death by a mechanism depending on c-myc and bcl-2 expression, Cell Tissue Res 316(2) (2004) 197-209. doi: 10.1007/s00441-004-0872-z

[99] G. Musso, R. Gambino, F. De Michieli, G. Biroli, A. Premoli, G. Pagano, S. Bo, M. Durazzo, M. Cassader, Nitrosative stress predicts the presence and severity of nonalcoholic fatty liver at different stages of the development of insulin resistance and metabolic syndrome: possible role of vitamin A intake, The American journal of clinical nutrition 86(3) (2007) 661-71. doi: $\underline{10.1093 / a j c n / 86.3 .661}$

[100] M.B. Afonso, P.M. Rodrigues, A.L. Simao, D. Ofengeim, T. Carvalho, J.D. Amaral, M.M. Gaspar, H. Cortez-Pinto, R.E. Castro, J. Yuan, C.M. Rodrigues, Activation of necroptosis in human and experimental cholestasis, Cell Death Dis 7(9) (2016) e2390. doi: $10.1038 /$ cddis.2016.280

[101] S.H. Caldwell, D.M. Crespo, The spectrum expanded: cryptogenic cirrhosis and the natural history of non-alcoholic fatty liver diseasePowell EE, Cooksley WGE, Hanson R, Searle J, Halliday JW, Powell LW. The natural history of nonalcoholic steatohepatitis: a follow-up study of forty-two patients for up to 21 years [Hepatology 1990; 11: 74-80], Journal of hepatology 40(4) (2004) 578-584. doi:

[102] S.K. Mantena, A.L. King, K.K. Andringa, A. Landar, V. Darley-Usmar, S.M. Bailey, Novel interactions of mitochondria and reactive oxygen/nitrogen species in alcohol mediated liver disease, World journal of gastroenterology : WJG 13(37) (2007) 4967-73. doi: 
[103] E. Vanni, A. Marengo, L. Mezzabotta, E. Bugianesi, Systemic complications of nonalcoholic fatty liver disease: when the liver is not an innocent bystander, Seminars in liver disease, Thieme Medical Publishers, 2015, pp. 236-249.

[104] I.C.M. Simoes, A. Fontes, P. Pinton, H. Zischka, M.R. Wieckowski, Mitochondria in non-alcoholic fatty liver disease, The international journal of biochemistry \& cell biology 95 (2018) 93-99. doi: 10.1016/j.biocel.2017.12.019

[105] N.E. Sunny, S. Kalavalapalli, F. Bril, T.J. Garrett, M. Nautiyal, J.T. Mathew, C.M. Williams, K. Cusi, Cross-talk between branched-chain amino acids and hepatic mitochondria is compromised in nonalcoholic fatty liver disease, American journal of physiology. Endocrinology and metabolism 309(4) (2015) E311-9. doi: 10.1152/ajpendo.00161.2015

[106] A.J. Sanyal, C. Campbell-Sargent, F. Mirshahi, W.B. Rizzo, M.J. Contos, R.K. Sterling, V.A. Luketic, M.L. Shiffman, J.N. Clore, Nonalcoholic steatohepatitis: association of insulin resistance and mitochondrial abnormalities, Gastroenterology 120(5) (2001) 1183-92. doi: $\underline{10.1053 / \text { gast.2001.23256 }}$

[107] R. Mehta, K. Jeiran, A.B. Koenig, M. Otgonsuren, Z. Goodman, A. Baranova, Z. Younossi, The role of mitochondrial genomics in patients with non-alcoholic steatohepatitis (NASH), BMC medical genetics 17(1) (2016) 63. doi: 10.1186/s12881-016-0324-0

[108] I.O. Goncalves, E. Passos, S. Rocha-Rodrigues, J.R. Torrella, D. Rizo, E. Santos-Alves, P. Portincasa, M.J. Martins, A. Ascensao, J. Magalhaes, Physical exercise antagonizes clinical and anatomical features characterizing Lieber-DeCarli diet-induced obesity and related metabolic disorders, Clin Nutr 34(2) (2015) 241-7. doi: 10.1016/j.clnu.2014.03.010

[109] A. Ascensao, M.J. Martins, E. Santos-Alves, I.O. Goncalves, P. Portincasa, P.J. Oliveira, J. Magalhaes, Modulation of hepatic redox status and mitochondrial metabolism by exercise: therapeutic strategy for liver diseases, Mitochondrion 13(6) (2013) 862-70. doi: 10.1016/j.mito.2013.07.002

[110] Z.M. Younossi, R. Loomba, M.E. Rinella, E. Bugianesi, G. Marchesini, B.A. Neuschwander-Tetri, L. Serfaty, F. Negro, S.H. Caldwell, V. Ratziu, K.E. Corey, S.L. Friedman, M.F. Abdelmalek, S.A. Harrison, A.J. Sanyal, J.E. Lavine, P. Mathurin, M.R. Charlton, N.P. Chalasani, Q.M. Anstee, K.V. Kowdley, J. George, Z.D. Goodman, K. Lindor, Current and future therapeutic regimens for nonalcoholic fatty liver disease and nonalcoholic steatohepatitis, Hepatology 68(1) (2018) 361-371. doi: $\underline{10.1002 / h e p .29724}$

[111] D. Schuppan, J.M. Schattenberg, Non-alcoholic steatohepatitis: pathogenesis and novel therapeutic approaches, J Gastroenterol Hepatol 28 Suppl 1(S1) (2013) 68-76. doi: 10.1111/jgh.12212

[112] E. Molina-Molina, R. Lunardi Baccetto, D.Q. Wang, O. de Bari, M. Krawczyk, P. Portincasa, Exercising the hepatobiliary-gut axis. The impact of physical activity performance, European journal of clinical investigation 48(8) (2018) e12958. doi: $\underline{10.1111 / e c i .12958}$

[113] G. Musso, M. Cassader, F. Rosina, R. Gambino, Impact of current treatments on liver disease, glucose metabolism and cardiovascular risk in non-alcoholic fatty liver disease (NAFLD): a systematic review and meta-analysis of randomised trials, Diabetologia 55(4) (2012) 885-904. doi: 10.1007/s00125$\underline{011-2446-4}$

[114] A. Nier, A. Brandt, I. Conzelmann, Y. Özel, I. Bergheim, Non-Alcoholic Fatty Liver Disease in Overweight Children: Role of Fructose Intake and Dietary Pattern, Nutrients 10(9) (2018). doi: $\underline{10.3390 / \text { nu10091329 }}$

[115] M.F. Abdelmalek, A. Suzuki, C. Guy, A. Unalp-Arida, R. Colvin, R.J. Johnson, A.M. Diehl, Increased fructose consumption is associated with fibrosis severity in patients with nonalcoholic fatty liver disease, Hepatology 51(6) (2010) 1961-1971. doi:

[116] J.M. Schwarz, S.M. Noworolski, A. Erkin-Cakmak, N.J. Korn, M.J. Wen, V.W. Tai, G.M. Jones, S.P. Palii, M. Velasco-Alin, K. Pan, B.W. Patterson, A. Gugliucci, R.H. Lustig, K. Mulligan, Effects of 
Dietary Fructose Restriction on Liver Fat, De Novo Lipogenesis, and Insulin Kinetics in Children With Obesity, Gastroenterology 153(3) (2017) 743-752. doi: 10.1053/i.gastro.2017.05.043

[117] M. Ekstedt, L.E. Franzen, M. Holmqvist, P. Bendtsen, U.L. Mathiesen, G. Bodemar, S. Kechagias, Alcohol consumption is associated with progression of hepatic fibrosis in non-alcoholic fatty liver disease, Scand J Gastroenterol 44(3) (2009) 366-74. doi: 10.1080/00365520802555991

[118] U.S. Department of Health and Human Services and U.S. Department of Agriculture. $2015-2020$ Dietary Guidelines for Americans. 8th Edition. December 2015. Available at http://health.gov/dietaryguidelines/2015/guidelines/. (2016). doi:

[119] F. Liu, X. Wang, G. Wu, L. Chen, P. Hu, H. Ren, H. Hu, Coffee Consumption Decreases Risks for Hepatic Fibrosis and Cirrhosis: A Meta-Analysis, PloS one 10(11) (2015) e0142457. doi: 10.1371/journal.pone.0142457

[120] J.W. Molloy, C.J. Calcagno, C.D. Williams, F.J. Jones, D.M. Torres, S.A. Harrison, Association of coffee and caffeine consumption with fatty liver disease, nonalcoholic steatohepatitis, and degree of hepatic fibrosis, Hepatology 55(2) (2012) 429-36. doi: 10.1002/hep.24731

[121] M. Noureddin, J.M. Mato, S.C. Lu, Nonalcoholic fatty liver disease: update on pathogenesis, diagnosis, treatment and the role of S-adenosylmethionine, Exp Biol Med (Maywood) 240(6) (2015) 80920. doi: $\underline{10.1177 / 1535370215579161}$

[122] Y. Rotman, A.J. Sanyal, Current and upcoming pharmacotherapy for non-alcoholic fatty liver disease, Gut 66(1) (2017) 180-190. doi: 10.1136/gutinl-2016-312431

[123] G.P. Aithal, J.A. Thomas, P.V. Kaye, A. Lawson, S.D. Ryder, I. Spendlove, A.S. Austin, J.G. Freeman, L. Morgan, J. Webber, Randomized, placebo-controlled trial of pioglitazone in nondiabetic subjects with nonalcoholic steatohepatitis, Gastroenterology 135(4) (2008) 1176-84. doi: 10.1053/i.gastro.2008.06.047

[124] R. Belfort, S.A. Harrison, K. Brown, C. Darland, J. Finch, J. Hardies, B. Balas, A. Gastaldelli, F. Tio, J. Pulcini, R. Berria, J.Z. Ma, S. Dwivedi, R. Havranek, C. Fincke, R. DeFronzo, G.A. Bannayan, S. Schenker, K. Cusi, A placebo-controlled trial of pioglitazone in subjects with nonalcoholic steatohepatitis, The New England journal of medicine 355(22) (2006) 2297-307. doi: 10.1056/NEJMoa060326

[125] K. Cusi, B. Orsak, F. Bril, R. Lomonaco, J. Hecht, C. Ortiz-Lopez, F. Tio, J. Hardies, C. Darland, N. Musi, A. Webb, P. Portillo-Sanchez, Long-Term Pioglitazone Treatment for Patients With Nonalcoholic Steatohepatitis and Prediabetes or Type 2 Diabetes Mellitus: A Randomized Trial, Annals of internal medicine 165(5) (2016) 305-15. doi: $\underline{10.7326 / \mathrm{M} 15-1774}$

[126] A.J. Sanyal, N. Chalasani, K.V. Kowdley, A. McCullough, A.M. Diehl, N.M. Bass, B.A. Neuschwander-Tetri, J.E. Lavine, J. Tonascia, A. Unalp, M. Van Natta, J. Clark, E.M. Brunt, D.E. Kleiner, J.H. Hoofnagle, P.R. Robuck, C.R.N. Nash, Pioglitazone, vitamin E, or placebo for nonalcoholic steatohepatitis, The New England journal of medicine 362(18) (2010) 1675-85. doi: 10.1056/NEJMoa0907929

[127] A.J. Sanyal, P.S. Mofrad, M.J. Contos, C. Sargeant, V.A. Luketic, R.K. Sterling, R.T. Stravitz, M.L. Shiffman, J. Clore, A.S. Mills, A pilot study of vitamin E versus vitamin E and pioglitazone for the treatment of nonalcoholic steatohepatitis, Clin Gastroenterol Hepatol 2(12) (2004) 1107-15. doi:

[128] S. Singh, R. Khera, A.M. Allen, M.H. Murad, R. Loomba, Comparative effectiveness of pharmacological interventions for nonalcoholic steatohepatitis: A systematic review and network metaanalysis, Hepatology 62(5) (2015) 1417-32. doi: 10.1002/hep.27999

[129] B.A. Neuschwander-Tetri, E.M. Brunt, K.R. Wehmeier, D. Oliver, B.R. Bacon, Improved nonalcoholic steatohepatitis after 48 weeks of treatment with the PPAR-gamma ligand rosiglitazone, Hepatology 38(4) (2003) 1008-17. doi: 10.1053/ihep.2003.50420 
[130] V. Ratziu, F. Charlotte, C. Bernhardt, P. Giral, M. Halbron, G. Lenaour, A. Hartmann-Heurtier, E. Bruckert, T. Poynard, L.S. Group, Long-term efficacy of rosiglitazone in nonalcoholic steatohepatitis: results of the fatty liver improvement by rosiglitazone therapy (FLIRT 2) extension trial, Hepatology 51(2) (2010) 445-53. doi: $10.1002 /$ hep.23270

[131] V. Ratziu, P. Giral, S. Jacqueminet, F. Charlotte, A. Hartemann-Heurtier, L. Serfaty, P. Podevin, J.M. Lacorte, C. Bernhardt, E. Bruckert, A. Grimaldi, T. Poynard, L.S. Group, Rosiglitazone for nonalcoholic steatohepatitis: one-year results of the randomized placebo-controlled Fatty Liver Improvement with Rosiglitazone Therapy (FLIRT) Trial, Gastroenterology 135(1) (2008) 100-10. doi: $\underline{10.1053 / \text { i.gastro.2008.03.078 }}$

[132] L. Sun, Q. Yuan, T. Xu, L. Yao, J. Feng, J. Ma, L. Wang, C. Lu, D. Wang, Pioglitazone Improves Mitochondrial Function in the Remnant Kidney and Protects against Renal Fibrosis in 5/6 Nephrectomized Rats, Front Pharmacol 8 (2017) 545. doi: 10.3389/fphar.2017.00545

[133] N. Chalasani, Z. Younossi, J.E. Lavine, M. Charlton, K. Cusi, M. Rinella, S.A. Harrison, E.M. Brunt, A.J. Sanyal, The diagnosis and management of nonalcoholic fatty liver disease: Practice guidance from the American Association for the Study of Liver Diseases, Hepatology 67(1) (2018) 328-357. doi: $\underline{10.1002 / h e p .29367}$

[134] L. European Association for the Study of the, D. European Association for the Study of, O. European Association for the Study of, EASL-EASD-EASO Clinical Practice Guidelines for the management of non-alcoholic fatty liver disease, Journal of hepatology 64(6) (2016) 1388-402. doi: 10.1016/i.jhep.2015.11.004

[135] M.J. Armstrong, P. Gaunt, G.P. Aithal, D. Barton, D. Hull, R. Parker, J.M. Hazlehurst, K. Guo, L.t. team, G. Abouda, M.A. Aldersley, D. Stocken, S.C. Gough, J.W. Tomlinson, R.M. Brown, S.G. Hubscher, P.N. Newsome, Liraglutide safety and efficacy in patients with non-alcoholic steatohepatitis (LEAN): a multicentre, double-blind, randomised, placebo-controlled phase 2 study, Lancet 387(10019) (2016) 679-90. doi: 10.1016/S0140-6736(15)00803-X

[136] J. Cui, L. Philo, P. Nguyen, H. Hofflich, C. Hernandez, R. Bettencourt, L. Richards, J. Salotti, A. Bhatt, J. Hooker, W. Haufe, C. Hooker, D.A. Brenner, C.B. Sirlin, R. Loomba, Sitagliptin vs. placebo for non-alcoholic fatty liver disease: A randomized controlled trial, Journal of hepatology 65(2) (2016) 36976. doi: $\underline{10.1016 / j . j h e p .2016 .04 .021}$

[137] T.R. Joy, C.A. McKenzie, R.G. Tirona, K. Summers, S. Seney, S. Chakrabarti, N. Malhotra, M.D. Beaton, Sitagliptin in patients with non-alcoholic steatohepatitis: A randomized, placebo-controlled trial, World journal of gastroenterology : WJG 23(1) (2017) 141-150. doi: $10.3748 /$ wjg.v23.i1.141

[138] V. Ratziu, S.A. Harrison, S. Francque, P. Bedossa, P. Lehert, L. Serfaty, M. Romero-Gomez, J. Boursier, M. Abdelmalek, S. Caldwell, J. Drenth, Q.M. Anstee, D. Hum, R. Hanf, A. Roudot, S. Megnien, B. Staels, A. Sanyal, G.-I.S. Group, Elafibranor, an Agonist of the Peroxisome Proliferator-Activated Receptor-alpha and -delta, Induces Resolution of Nonalcoholic Steatohepatitis Without Fibrosis Worsening, Gastroenterology 150(5) (2016) 1147-1159 e5. doi: 10.1053/i.gastro.2016.01.038

[139] A. Di Ciaula, G. Garruti, R. Lunardi Baccetto, E. Molina-Molina, L. Bonfrate, D.Q. Wang, P. Portincasa, Bile Acid Physiology, Annals of hepatology 16(Suppl. 1: s3-105.) (2017) s4-s14. doi: $\underline{10.5604 / 01.3001 .0010 .5493}$

[140] G. Porez, J. Prawitt, B. Gross, B. Staels, Bile acid receptors as targets for the treatment of dyslipidemia and cardiovascular disease Thematic Review Series: New Lipid and Lipoprotein Targets for the Treatment of Cardiometabolic Diseases, Journal of lipid research 53(9) (2012) 1723-1737. doi:

[141] B.A. Neuschwander-Tetri, R. Loomba, A.J. Sanyal, J.E. Lavine, M.L. Van Natta, M.F. Abdelmalek, N. Chalasani, S. Dasarathy, A.M. Diehl, B. Hameed, K.V. Kowdley, A. McCullough, N. Terrault, J.M. Clark, J. Tonascia, E.M. Brunt, D.E. Kleiner, E. Doo, N.C.R. Network, Farnesoid X nuclear receptor ligand obeticholic acid for non-cirrhotic, non-alcoholic steatohepatitis (FLINT): a multicentre, randomised, placebo-controlled trial, Lancet 385(9972) (2015) 956-65. doi: 10.1016/S0140$\underline{6736(14) 61933-4}$ 
[142] A.C. Calkin, P. Tontonoz, Transcriptional integration of metabolism by the nuclear sterol-activated receptors LXR and FXR, Nature reviews. Molecular cell biology 13(4) (2012) 213-24. doi: $\underline{10.1038 / \mathrm{nrm} 3312}$

[143] T.Q. de Aguiar Vallim, E.J. Tarling, P.A. Edwards, Pleiotropic roles of bile acids in metabolism, Cell metabolism 17(5) (2013) 657-69. doi: 10.1016/j.cmet.2013.03.013

[144] Y. Wei, S.E. Clark, J.P. Thyfault, G.M. Uptergrove, W. Li, A.T. Whaley-Connell, C.M. Ferrario, J.R. Sowers, J.A. Ibdah, Oxidative stress-mediated mitochondrial dysfunction contributes to angiotensin IIinduced nonalcoholic fatty liver disease in transgenic Ren2 rats, The American journal of pathology 174(4) (2009) 1329-37. doi: 10.2353/ajpath.2009.080697

[145] C. Xie, C. Jiang, J. Shi, X. Gao, D. Sun, L. Sun, T. Wang, S. Takahashi, M. Anitha, K.W. Krausz, A.D. Patterson, F.J. Gonzalez, An Intestinal Farnesoid X Receptor-Ceramide Signaling Axis Modulates Hepatic Gluconeogenesis in Mice, Diabetes 66(3) (2017) 613-626. doi: 10.2337/db16-0663

[146] A. Ferramosca, M. Di Giacomo, V. Zara, Antioxidant dietary approach in treatment of fatty liver: New insights and updates, World journal of gastroenterology : WJG 23(23) (2017) 4146-4157. doi: $\underline{10.3748 / \text { wig.v23.i23.4146 }}$

[147] J. Asin-Cayuela, A.R. Manas, A.M. James, R.A. Smith, M.P. Murphy, Fine-tuning the hydrophobicity of a mitochondria-targeted antioxidant, FEBS Lett 571(1-3) (2004) 9-16. doi: 10.1016/j.febslet.2004.06.045

[148] T.I. Rokitskaya, S.S. Klishin, Severina, II, V.P. Skulachev, Y.N. Antonenko, Kinetic analysis of permeation of mitochondria-targeted antioxidants across bilayer lipid membranes, The Journal of membrane biology 224(1-3) (2008) 9-19. doi: $10.1007 / \mathrm{s} 00232-008-9124-6$

[149] R.A. Smith, C.M. Porteous, A.M. Gane, M.P. Murphy, Delivery of bioactive molecules to mitochondria in vivo, Proceedings of the National Academy of Sciences of the United States of America 100(9) (2003) 5407-12. doi: 10.1073/pnas.0931245100

[150] C. Feillet-Coudray, G. Fouret, R. Ebabe Elle, J. Rieusset, B. Bonafos, B. Chabi, D. Crouzier, K. Zarkovic, N. Zarkovic, J. Ramos, E. Badia, M.P. Murphy, J.P. Cristol, C. Coudray, The mitochondrialtargeted antioxidant MitoQ ameliorates metabolic syndrome features in obesogenic diet-fed rats better than Apocynin or Allopurinol, Free radical research 48(10) (2014) 1232-46. doi: $\underline{10.3109 / 10715762.2014 .945079}$

[151] G. Fouret, E. Tolika, J. Lecomte, B. Bonafos, M. Aoun, M.P. Murphy, C. Ferreri, C. Chatgilialoglu, E. Dubreucq, C. Coudray, C. Feillet-Coudray, The mitochondrial-targeted antioxidant, MitoQ, increases liver mitochondrial cardiolipin content in obesogenic diet-fed rats, Biochimica et biophysica acta 1847(10) (2015) 1025-35. doi: 10.1016/..bbabio.2015.05.019

[152] J.R. Mercer, E. Yu, N. Figg, K.K. Cheng, T.A. Prime, J.L. Griffin, M. Masoodi, A. Vidal-Puig, M.P. Murphy, M.R. Bennett, The mitochondria-targeted antioxidant MitoQ decreases features of the metabolic syndrome in ATM+/-/ApoE-/- mice, Free radical biology \& medicine 52(5) (2012) 841-9. doi: $\underline{10.1016 / \text { j.freeradbiomed.2011.11.026 }}$

[153] A. Dhanasekaran, S. Kotamraju, S.V. Kalivendi, T. Matsunaga, T. Shang, A. Keszler, J. Joseph, B. Kalyanaraman, Supplementation of endothelial cells with mitochondria-targeted antioxidants inhibit peroxide-induced mitochondrial iron uptake, oxidative damage, and apoptosis, The Journal of biological chemistry 279(36) (2004) 37575-87. doi: $\underline{10.1074 / \text { jbc.M404003200 }}$

[154] E.J. Gane, F. Weilert, D.W. Orr, G.F. Keogh, M. Gibson, M.M. Lockhart, C.M. Frampton, K.M. Taylor, R.A. Smith, M.P. Murphy, The mitochondria-targeted anti-oxidant mitoquinone decreases liver damage in a phase II study of hepatitis $C$ patients, Liver international : official journal of the International Association for the Study of the Liver 30(7) (2010) 1019-26. doi: 10.1111/j.1478-3231.2010.02250.x 
[155] L. Baselga-Escudero, V. Souza-Mello, A. Pascual-Serrano, T. Rachid, A. Voci, I. Demori, E. Grasselli, Beneficial effects of the Mediterranean spices and aromas on non-alcoholic fatty liver disease, Trends in Food Science \& Technology 61 (2017) 141-159. doi: 10.1016/j.tifs.2016.11.019

[156] R. Saller, R. Meier, R. Brignoli, The use of silymarin in the treatment of liver diseases, Drugs 61(14) (2001) 2035-2063. doi: Doi 10.2165/00003495-200161140-00003

[157] M. Trappoliere, A. Caligiuri, M. Schmid, C. Bertolani, P. Failli, F. Vizzutti, E. Novo, C. di Manzano, F. Marra, C. Loguercio, M. Pinzani, Silybin, a component of sylimarin, exerts anti-inflammatory and antifibrogenic effects on human hepatic stellate cells, Journal of hepatology 50(6) (2009) 1102-11. doi: 10.1016/i.jhep.2009.02.023

[158] H. Solhi, R. Ghahremani, A.M. Kazemifar, Z. Hoseini Yazdi, Silymarin in treatment of non-alcoholic steatohepatitis: A randomized clinical trial, Caspian J Intern Med 5(1) (2014) 9-12. doi:

[159] C. Loguercio, P. Andreone, C. Brisc, M.C. Brisc, E. Bugianesi, M. Chiaramonte, C. Cursaro, M. Danila, I. de Sio, A. Floreani, M.A. Freni, A. Grieco, M. Groppo, R. Lazzari, S. Lobello, E. Lorefice, M. Margotti, L. Miele, S. Milani, L. Okolicsanyi, G. Palasciano, P. Portincasa, P. Saltarelli, A. Smedile, F. Somalvico, A. Spadaro, I. Sporea, P. Sorrentino, R. Vecchione, C. Tuccillo, C. Del Vecchio Blanco, A. Federico, Silybin combined with phosphatidylcholine and vitamin $\mathrm{E}$ in patients with nonalcoholic fatty liver disease: a randomized controlled trial, Free radical biology \& medicine 52(9) (2012) 1658-65. doi: $\underline{10.1016 / \text { j.freeradbiomed.2012.02.008 }}$

[160] G. Vecchione, E. Grasselli, A. Voci, F. Baldini, I. Grattagliano, D.Q. Wang, P. Portincasa, L. Vergani, Silybin counteracts lipid excess and oxidative stress in cultured steatotic hepatic cells, World journal of gastroenterology : WJG 22(26) (2016) 6016-26. doi: 10.3748/wig.v22.i26.6016

[161] A. Fu, X. Shi, H. Zhang, B. Fu, Mitotherapy for Fatty Liver by Intravenous Administration of Exogenous Mitochondria in Male Mice, Front Pharmacol 8 (2017) 241. doi: 10.3389/fphar.2017.00241

[162] T.A. Ajith, Role of mitochondria and mitochondria-targeted agents in non-alcoholic fatty liver disease, Clinical and experimental pharmacology \& physiology 45(5) (2018) 413-421. doi: $\underline{10.1111 / 1440-1681.12886}$

[163] S.C. Cazanave, J.L. Mott, S.F. Bronk, N.W. Werneburg, C.D. Fingas, X.W. Meng, N. Finnberg, W.S. El-Deiry, S.H. Kaufmann, G.J. Gores, Death receptor 5 signaling promotes hepatocyte lipoapoptosis, The Journal of biological chemistry 286(45) (2011) 39336-48. doi: 10.1074/jbc.M111.280420 


\section{Legend to Figures}

\section{Figure 1}

Light micrographs of human liver stained with hematoxylin-eosin.

(A) simple steatosis showing intracellular fat deposition organized as droplets confluent to form vacuoles;

(B) steatohepatitis showing fatty infiltration of hepatocytes, inflammation and fibrotic septa determining significant changes of the liver architecture. Magnification: 200x.

Courtesy of Maria L. Caruso, MD, Dept of Pathology, National Institute of Gastroenterology "S de Bellis", Castellana Grotte, Bari, Italy

\section{Figure 2}

\section{Distinct regulatory functions of adipocytes in lean and obese subjects.}

In lean subjects, up regulated uptake of long-chain fatty acids (LCFA) by adipocytes from the portal vein occurs i.e. adipocytes import LCFA intermittently post-prandially; LCFA accumulate into large droplets mainly of triglycerides (TGs). Lipolysis releases LCFA according to the metabolic needs. In the obesogenic scenario, subjects accumulate expanded visceral adiposity, without preventing the effect of lipases; this condition causes excessive flux of LCFA into portal vein with subsequent lipotoxic deposition into non-adipose cells (cardiac myocytes, hepatocytes, pancreatic $\beta$-cells and striated muscle cells).

\section{Figure 3.}

\section{Lipid accumulation in NAFLD.}

A) In a condition of expanded visceral adiposity and insulin resistance, events include increased flow and uptake of long-chain fatty acids (LCFA) in the liver, increased uptake of dietary fats and sugars, intestinal dysbiosis, and decreased export of VLDL.

B) Events contributing to hepatic lipid-induced insulin resistance in the liver. The hepatocyte is overloaded with LCFA leading to activation of diacylglyceride (DAG) and 
epsilon isoform of protein kinase $C(P K C \varepsilon)$. Further steps include defective mitochondrial function and decreased rates of incorporation of DAG into triacylglycerides, defective insulin receptor (IR-1), decreased glycogen synthesis, along with increased hepatic gluconeogenesis.

Abbreviations: ApoB, apolipoprotein B; ChREBP, carbohydrate-responsive element-binding protein; DNL, de novo lipogenesis; LCFA, long-chain fatty acids; IL, interleukin; FATP5, fatty acid transport protein 5 (bile acyl-CoA synthetase); PKC $\varepsilon$ protein kinase $\mathrm{C} \varepsilon$; SREBP, sterol regulatory element-binding protein 1; TNF, tumor necrosis factor; VLDL, very low density lipoprotein. Symbols: $\uparrow$, increased, $\downarrow$.

Adapted from Portincasa P, Wang DQH. Nonalcoholic fatty liver and gallstone disease. In: Wang DQH, Portincasa P, eds. Gallstones. Recent advances in epidemiology, pathogenesis, diagnosis and management. New York: Nova Science Publisher Inc., 2017:387-414 [163] and Grattagliano I, De Bari O, Di Palo D, Montecucco F, Carbone F, Oliveira P, Wang DQH, Portincasa P. Mitochondria in liver diseases. In: Oliveira P, ed. Mitochondrial Biology and Experimental Therapeutics. Cham, Switzerland: Springer Nature, 2018:91-126.[82]

\section{Figure 4}

Pathways leading to hepatocyte injury, death, inflammation and fibrosis during NAFLD and NASH.

Increased accumulation of LCFA activate endoplasmic reticulum stress, mitochondrial dysfunction, death receptors, macrophagic and stellate cell activation. The role of microbiotaderived endotoxins might contribute to the inflammatory changes.

Abbreviations: DAMPs, damage-associated molecular patterns; DR5, death receptor 5; LCFA, long-chain fatty acids; ROS, reactive oxygen species; TLRs, Toll-like receptors; TNFRSF1A, tumor necroptosis factor receptor superfamily member $1 \mathrm{~A}$

Adapted from Portincasa P, Wang DQH. Nonalcoholic fatty liver and gallstone disease. In: Wang DQH, Portincasa P, eds. Gallstones. Recent advances in epidemiology, pathogenesis, 
diagnosis and management. New York: Nova Science Publisher Inc., 2017:387-414 [50] and Grattagliano I, De Bari O, Di Palo D, Montecucco F, Carbone F, Oliveira P, Wang DQH, Portincasa P. Mitochondria in liver diseases. In: Oliveira P, ed. Mitochondrial Biology and Experimental Therapeutics. Cham, Switzerland: Springer Nature, 2018:91-126.[ㄹ]

\section{Figure 5}

Structures of agents targeting the steatotic liver: peroxisome proliferator-activated receptors (PPARs) pioglitazone and rosiglitazone; sitagliptin (dipeptidyl peptidase-4 inhibitor). Elafibranor is an agonist of peroxisome proliferator-activated receptors $\alpha$ and $\delta$, involved in mechanisms improving insulin sensitivity, glucose homeostasis, lipid metabolism and inflammation). In particular, pioglitazone possesses protective mitochondrial effects, preventing the leakage of cytochrome $\mathrm{c}$ from mitochondria, stabilizing the mitochondrial transmembrane potential, inhibiting ROS generation and activating the electron transport chain complexes III and I.

\section{Figure 6}

Bile acid (BA) biosynthesis in humans. The primary BAs are synthetized in the liver starting from cholesterol as trihydroxy cholic acid (CA) and dihydroxy chenodeoxycholic acid (CDCA). The biosynthetic pathways include the "classical pathway" where a cytochrome P450 oxidase, the cholesterol 7a-hydroxylase (CYP7A1), induces the 7a-hydroxylation of cholesterol. The "alternative" pathway occurs with another a cytochrome P450 oxidase, the sterol-27hydroxylase (CYP27A1), and produces mainly CA. The two primary BAs account for more than $75 \%$ of total BA production. In the intestine (mainly colon), the microbiota operates by $7 \alpha-$ dehydroxylation on CA and CDCA to synthesize the «secondary» dihydroxy deoxycholic acid (DCA) and the monohydroxy lithocholic acid (LCA). CDCA is also $7 \alpha$-dehydrogenated to dihydroxy 7a-oxo-LCA further metabolized to its $7 \beta$-epimer and "tertiary' bile acid the dihydroxy ursodeoxycholic acid (UDCA). [139]. 


\section{Figure 7}

Structure of the potent farnesoid $\mathrm{X}$ receptor (FXR) activator 6-ethylchenodeoxycholic acid (obeticholic acid, OCA). The structure of chenodeoxycholic acid appears for comparison.

\section{Figure 8}

Structures of antioxidant compounds used for the treatment of liver steatosis, with results showing improvement of mitochondrial function. 

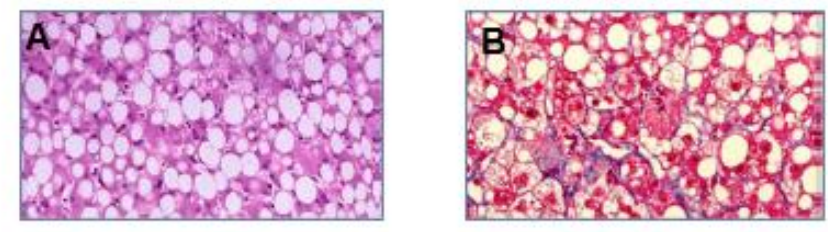

Figure 1 


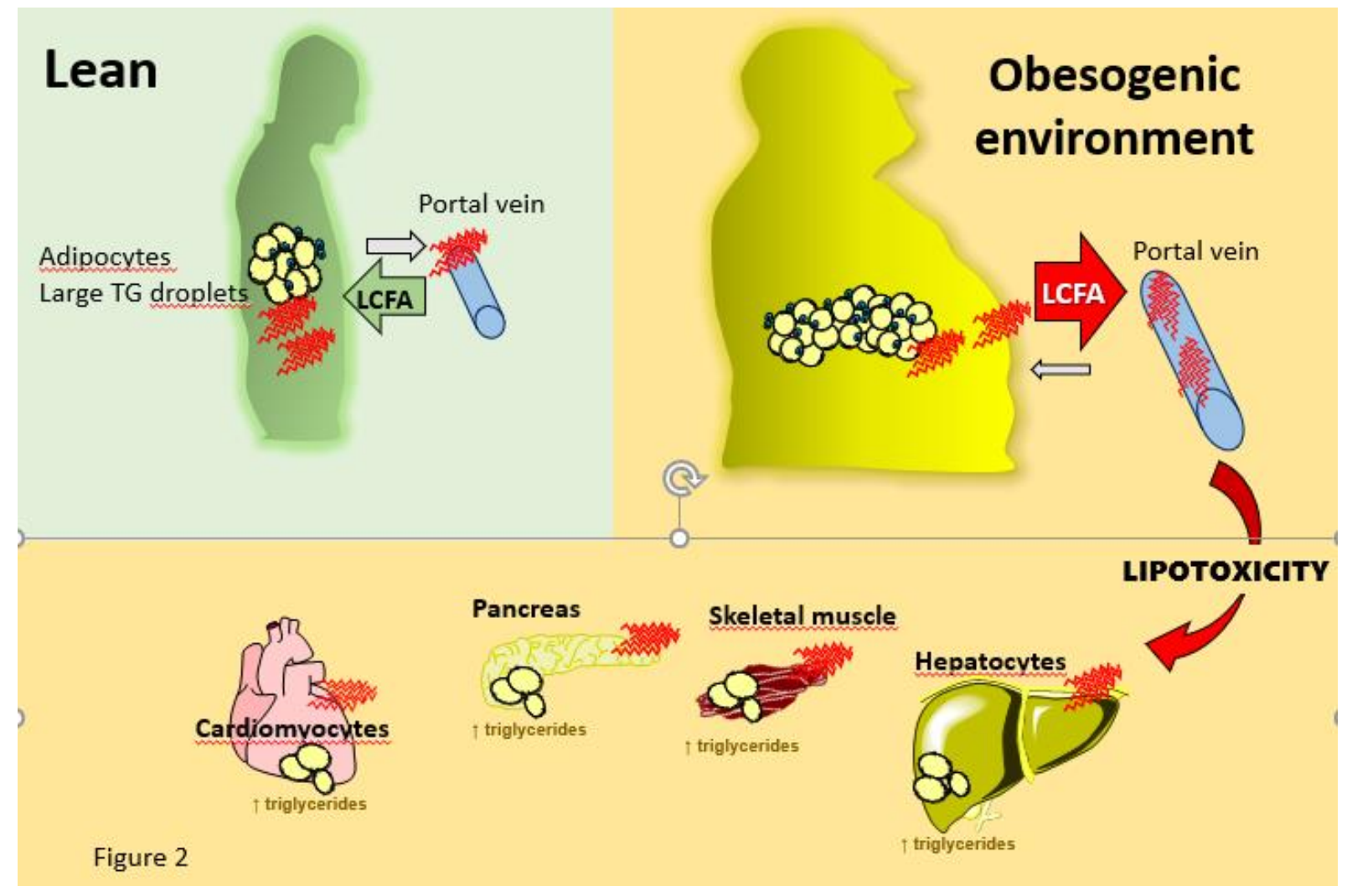


Figure $3 \mathrm{~A}$

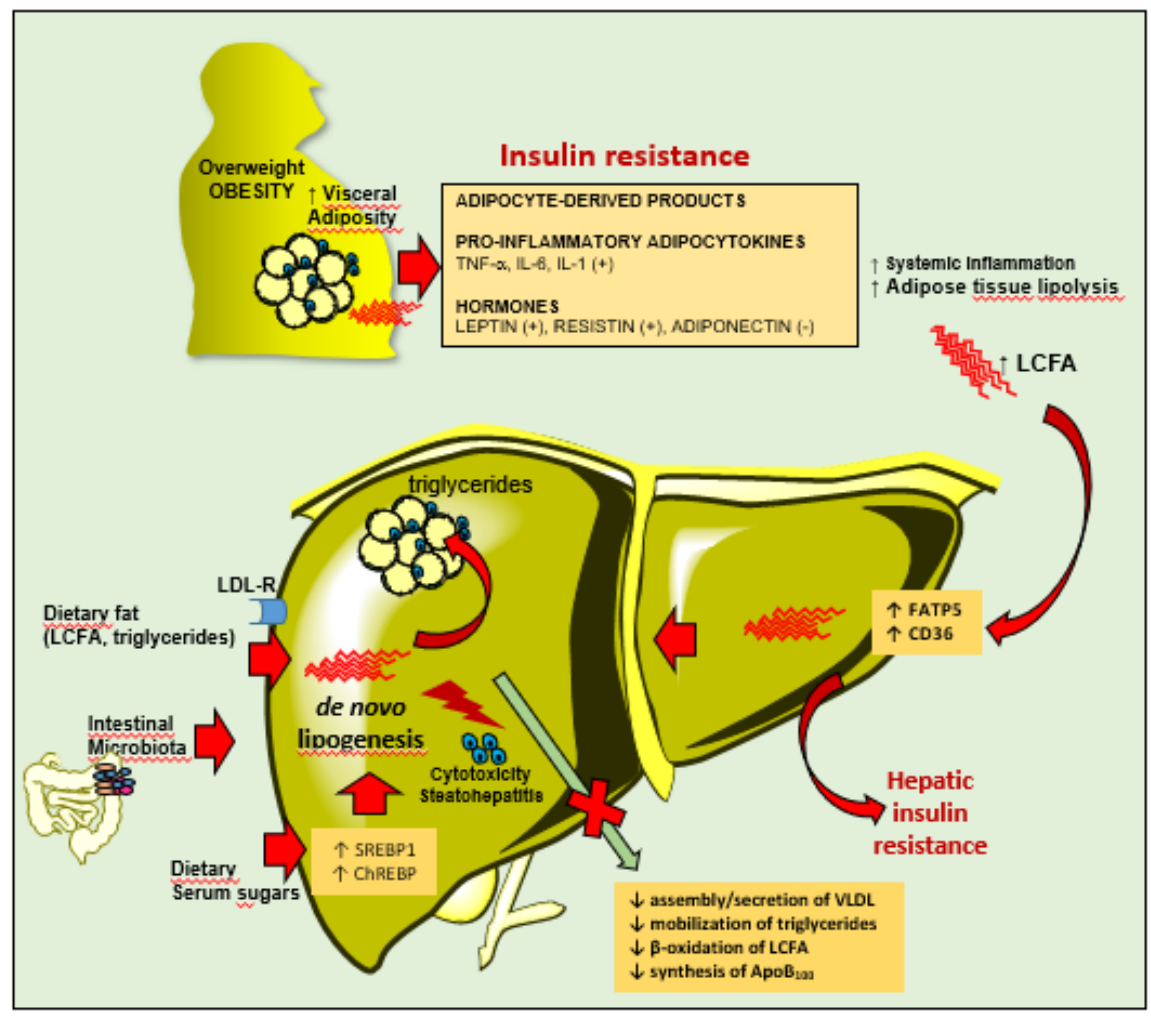




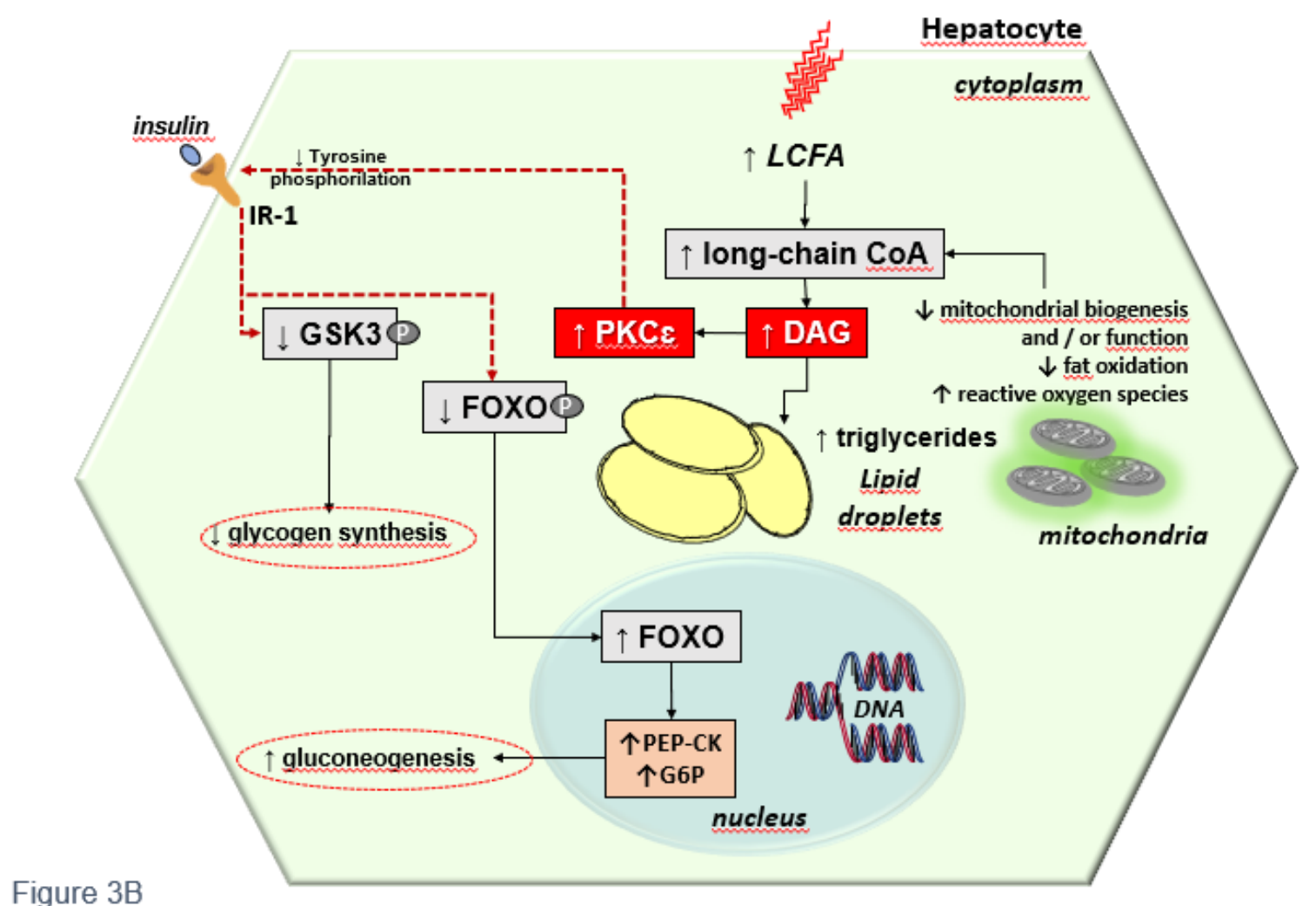

Figure 3B 


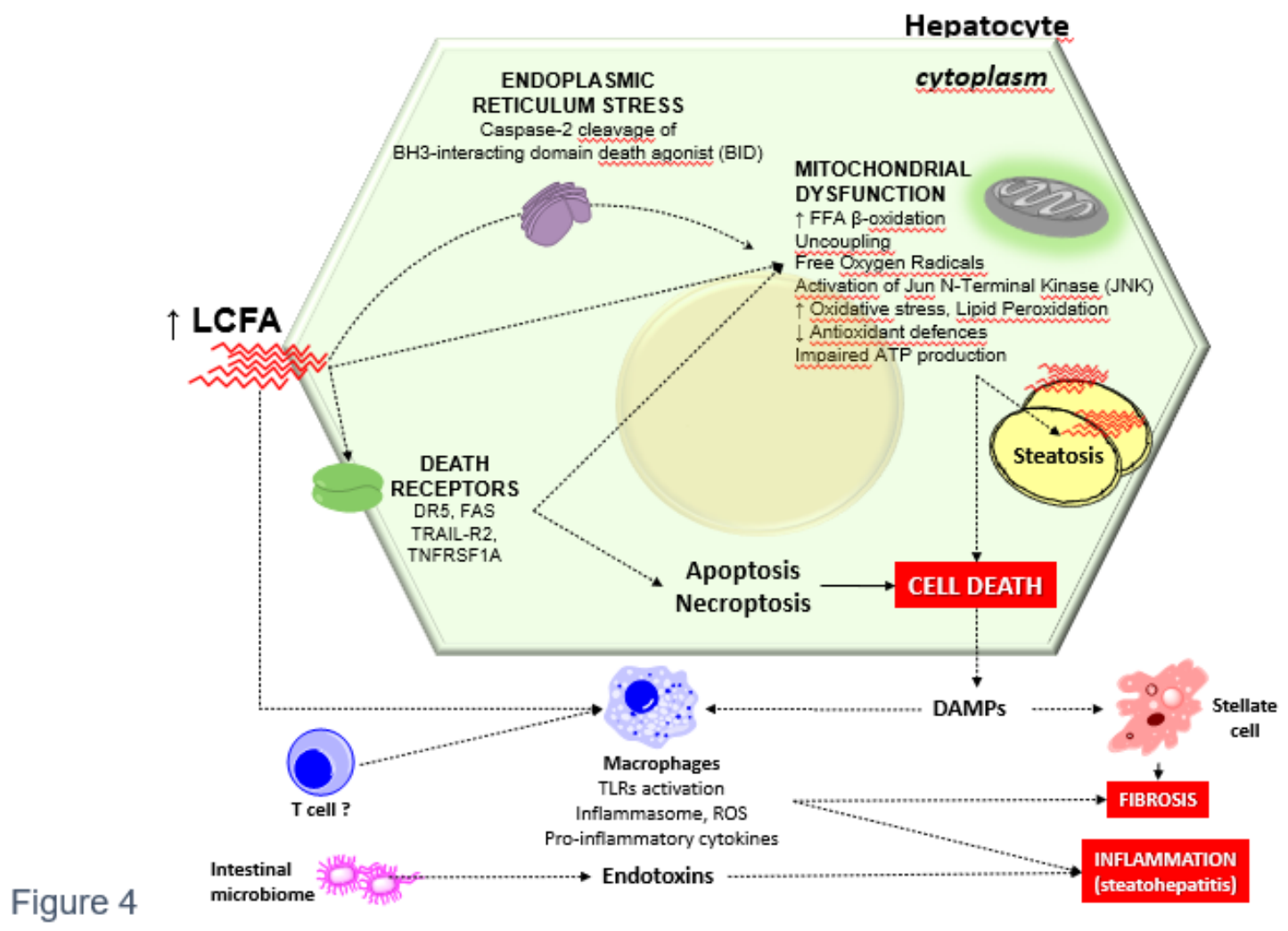




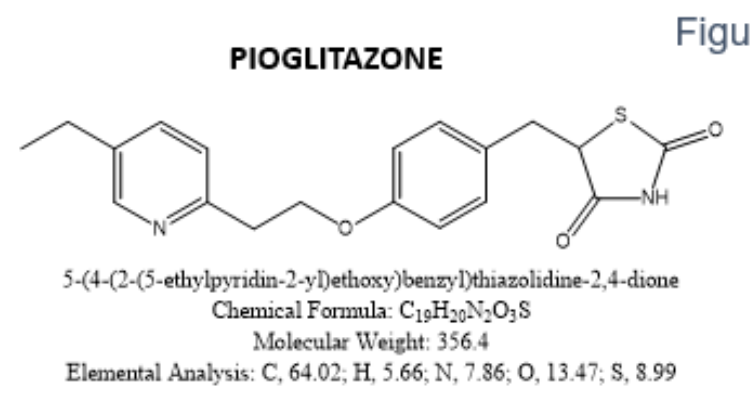<smiles>N[C@@H](CC(=O)N1CCn2c(nnc2C(F)(F)F)C1)Cc1cc(F)c(F)cc1F</smiles>

(R)-3-amino-1-(3-(trifluoromethyl)-5,6-dilhydro-[1,2,4]triazolo[4,3-a]pyrazin$7(8 H)$-yl $)-4-(2,4,5$-trifluorophenyl)butan-1-one Chemical Formula: $\mathrm{C}_{16} \mathrm{H}_{15} \mathrm{~F}_{6} \mathrm{~N}_{5} \mathrm{O}$ Molecular Weight: 407.3

Elemental Analysis: C, 47.18; H, 3.71; F, 27.99; N, 17.19; O, 3.93
Figure 5

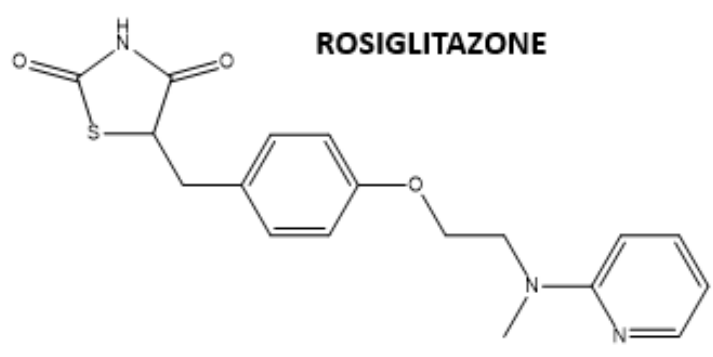

5-(4-(2-(methyl(pyridin-2-yl)amino)ethoxy)benzyl)thiazolidine-2,4-dione

Chemical Formula: $\mathrm{C}_{37} \mathrm{H}_{39} \mathrm{~N}_{5} \mathrm{O}_{6} \mathrm{~S}_{2}$ Molecular Weight: 713.9

Elemental Analysis: C, $62.25 ; \mathrm{H}, 5.51 ; \mathrm{N}, 9.81 ; \mathrm{O}, 13.45 ; \mathrm{S}, 8.98$

ELAFIBRANOR<smiles>CSc1ccc(C(=O)/C=C/c2cc(C)c(OC(C)(C)C(=O)O)c(C)c2)cc1</smiles>

(E)-2-(2,6-dimethyl-4-(3-(4-(methylthio)phenyl)-3-oxoprop-1-en-1-yl)phenoxy)-2methylpropanoic acid

Chemical Formula: $\mathrm{C}_{22} \mathrm{H}_{24} \mathrm{O}_{4} \mathrm{~S}$

Molecular Weight: 384.5

Elemental Analysis: C, $68.73 ; \mathrm{H}, 6.29 ; \mathrm{O}, 16.64 ; \mathrm{S}, 8.34$ 


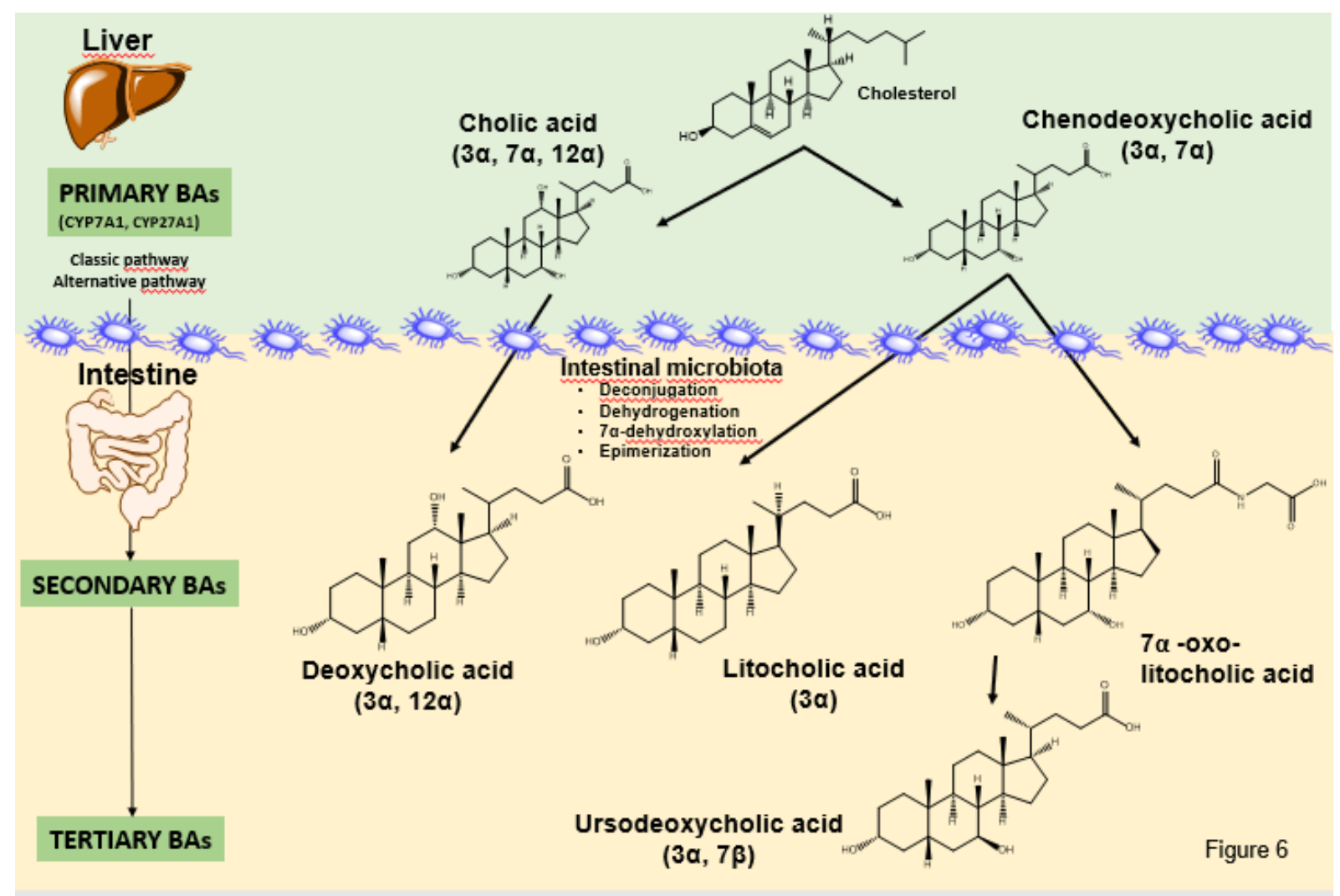




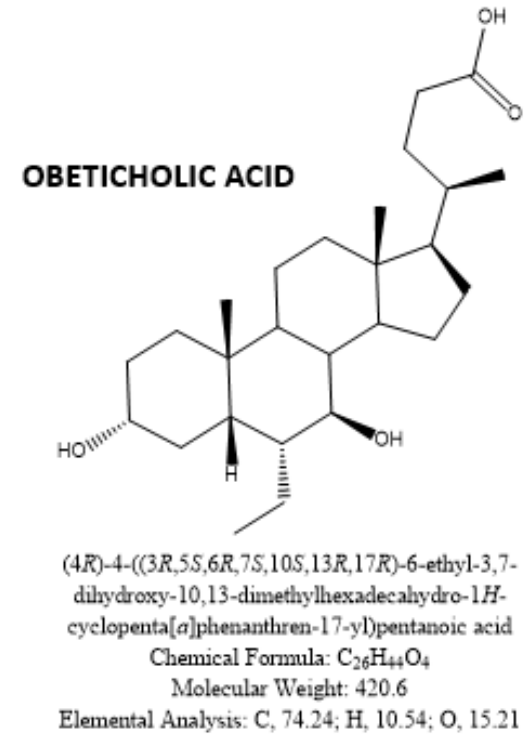

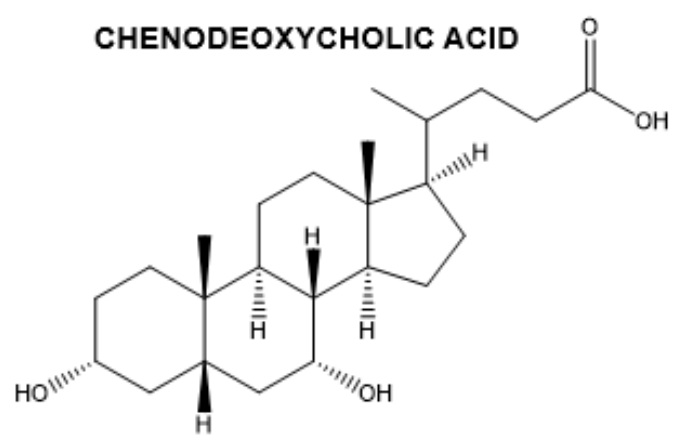

Figure 7 
TEMPOL<smiles>CC1(C)CCCC(C)(C)N1[O]</smiles>

Chemical Formula: $\mathrm{C}_{9} \mathrm{H}_{18} \mathrm{NO}^{\text {* }}$

Molecular Weight: 156.2

Elemental Analysis: C, $69.18 ; \mathrm{H}$

$11.61 ; \mathrm{N}, 8.96 ; \mathrm{O}, 10.24$

\section{MITOQUINONE (MITO-Q)}

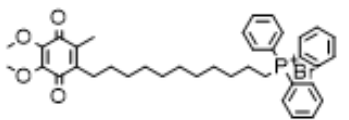

Chemical Formula: $\mathrm{C}_{38} \mathrm{H}_{40} \mathrm{BrO}_{4} \mathrm{P}$ Molecular Weight: 677.7

Elemental Analysis: C, $67.35 ; \mathrm{H}, 6.84 ; \mathrm{Br}, 11.79 ; \mathrm{O}, 9.44 ; \mathrm{P}, 4.57$

Figure 8
RESVERATROL<smiles>Oc1ccc(/C=C/c2cc(O)cc(O)c2)cc1</smiles>

(E)-5-(4-hydroxystyryl)benzene-1,3-diol Chemical Formula: $\mathrm{C}_{14} \mathrm{H}_{12} \mathrm{O}_{3}$ Molecular Weight: 228.2

Elemental Analysis: C, 73.67; H, 5.30; O, 21.03

SILYBIN<smiles>COc1cc([C@H]2Oc3cc([C@@H]4Oc5cc(O)cc(O)c5C(=O)[C@H]4O)ccc3O[C@@H]2CO)ccc1O</smiles>

Chemical Formula: $\mathrm{C}_{25} \mathrm{H}_{22} \mathrm{O}_{10}$ Molecular Weight: 482.4

Elemental Analysis: C, $62.24 ; \mathrm{H}, 4.60 ; 0,33.16$ 